\title{
Current Research on Multiple Births
}

\section{ANNUAL BIBLIOGRAPHY - 1988}

Produced by a MEDLARS search of the worlwide medical literature received by the National Library of Medicine, U.S. Public Health Service between November 1987 and April 1988. Sponsored by the Center for the Study of Multiple Birth, Chicago, Illinois.

\section{Subject Sections*}

Title, authors, and journal source, alphabetized by journal:
$\diamond \quad$ Behavior and Physiology
$\diamond \quad$ Genetic Traits and Methods
$\diamond \quad$ Obstetrics and Pediatrics
$\diamond \quad$ General

\section{Author Section}

Authors, titles, journal source, and abstract (if available), alphabetized and cross-indexed by all authors.

\footnotetext{
*The first three subject sections include other topics related to these headings. Classification is performed automatically on the basis of keywords. Some articles may appear in two or three of the specific subject sections.
} 
+ Design and sampling considerations, response rates, and representativeness in a Finnish Twin Family Study. Kaprio J, et al. Acta Genet Med Gemellol (Roma) 1987; 36(1):79-93

+ Constrained maximum likelihood analysis of familial resemblance of twins and their parents. Boomsma DI, et al.

Acts Genet Med Gemeliol (Roma) 1987; 36(1):29-39

t The analysis of marital interaction in cross-sectional twin data. Heath AC. Acta Genet Med Gemellol (Roma) 1987; $36(1): 41-9$

+ The Vietnam Era Twin (VET) Registry: ascertainment bias. Goldberg J, et al. Acta Genet Med Gemellol (Roma) 1987; 36(1):67-78

+ A new method for representing mental growth. Wilson RS. Acta Genet Med Gemellol (Roma) 1987;36(2):121-34

+ Developmental research of twin's temperament. Matheny AP Jr.

Acta Genet Med Gemellol (Roma) 1987; 36(2): 135-43

+ Longitudinal research on temperament in twins. Torgersen AM.

Acta Genet Med Gemellol (Roma) 1987; 36(2): $145-54$

+ Nature-nurture interaction in different types of school environments. A longitudinal study. Fischbein S.

Acta Genet Med Gemellol (Roma) 1987; 36(2): $155-63$

+ Restrictiveness-permissiveness of their environment as perceived by kibbutz twins and singletons. Guttman $\mathbf{R}$, et al

Acta Genet Med Gemellol (Roma) 1987; 36(2):165-70

$\dagger$ Multivariate analysis of genetic and environmental influences for longitudinal height and weight data. Fischbein $\mathbf{S}$, et al

Acta Genet Med Gemellol (Roma) 1987; 36(2):171-80

+ Birthweight differences, the transfusion syndrome and the cognitive development of monozygotic twins. O'Brien PJ, et al.

Acta Genet Med Gemellol (Roma) 1987: 36(2):181-96 (46 ref.)

† Growth characteristics in twins and higher order multiple births. Buckler JM, et al.

Acts Genet Med Gemellol (Roms) 1987; 36(2): 197-208

+ Weight and height growth. in twins and children born in the last decade. Alfieri $A$, et al.

Acta Genet Med Gemellol (Roma) 1987; 36(2):209-11

+ Speech and language develorment in preschool twins. Hay DA, et al.

Acta Genet Med Gemellol (Roma) 1987; $36(2): 213-23$

† The expectation and parentage of twins. A study on the language development of twin infants. Alin-Akerman $B$.

Acta Genet Med Gemellol (Roma) 1987; 36(2):225-32

- Autonomous languages of twins. Bakker P. Acta Genet Med Gemellol (Roma) 1987; 36(2):233-8

+ Early influences on the school social adjustment of twins. Hay DA, et al.

Acta Genet Med Gemellol (Roma) 1987; 36(2):239-48

+ indicates that an abstract appears with the citation in the author section
+ Dominance and submissiveness between twins. I. Perinatal and development aspects. Moilanen I. Acta Genet Med Gemellol (Roma) 1987; 36(2):249-55

† Dominance and submissiveness between twins. II. Consequences for mental health. Moilanen I. Acta Genet Med Gemellol (Roma) 1987, 36(2):257-65

$\uparrow$ Family history and birthweight in monozygotic twins concordant and discordant for psychosis. Lewis SW, et al.

Acta Genet Med Gemellol (Roma) 1987; 36(2):267-73

+ Myopia and stature. Teikari JM. Acta Ophthalmol (Copenh) 1987 Dec;65(6):673-6

$\dagger$ Social and genetic influences on drinking patterns of adult men: a study of 5638 Finnish twin brothers. Kaprio J, et al. Alcohol Alcohol 1987; Suppl 1:373-7

Necrotizing enterocolitis in multiple gestation [letter] Goldman HI. Am J Dis Child 1987 Dec; 141(12):1252-3

+ Developmental outcome following posthemorrhagic hydrocephalus in preterm infants. Comparison of twins discordant for hydrocephalus. Davis SL, et al.

Am J Dis Child 1987 Novi141(11):1170-4

$\dagger$ Genetic variance of weight and length in infant twins. Levine RS, et al. Am J Epidemiol 1987 Nov; 126(5):929-35

$\dagger$ Twinning, nonrighthandedness, and fusion malformations: evidence for heritable causal elements held in common. Boklage CE. Am J Med Genet 1987 Sep;28(1):67-84 (113 ref.)

$\dagger \mathrm{X}$-linked mental retardation with marfanoid habitus. Fryns JP, et al. Am J Med Genet 1987 Oct:28(2):267-74 (4 ref.)

† The length of the human umbilical cord in twin pregnancies. Soernes $T$, et al.

Am J Obstet Gynecol 1987 Nov;157(5):1229-30

† Developmental differences between singletons and twins in distributions of dental diameter asymmetries. Boklage CE.

Am J Phys Anthropol 1987 Nov;74(3):319-31

Paradoxical reactions to benzodiazepines--a genetically determined phenomenon? Short TG, et al. Anpesth Intensive Care 1987 Aug; 15(3):330-1

Testing genetic models for multiple symptoms: an application to the genetic analysis of liability to depression. Eaves LJ, et al. Behav Genet 1987 Jul;17(4):331-41

Recruitment bias in twin research: the rule of two-thirds reconsidered. Lykken DT, et al.

Behav Genet 1987 Jul;17(4):343-62

Genetic and environmental factors in primary dysmenorrhea and its relationship to anxiety, depression, and neuroticism. Silberg $J \mathbf{L}$, et al Behav Genet 1987 Jul;17(4):363-83

No genetic effect on variation in field dependence: a study of rod-and-frame scores in families of monozygotic twins. Tambs K. Behav Genet 1987 Sep; 17(5):493-502

Mothers' beginning relationship with twins. Anderson A, et al. Birth 1987 Jun; 14(2):94-8

+ Brainstem auditory evoked responses alteration in twin neonates. Delorme C, et al. Brain Dev 1987. 9(3):319-20

† A set of monozygotic twins with Rett syndrome Coleman M, et al. Brain Dev 1987;9(5):475-8

$\uparrow$ Attentional and perseverative impairment in two cases of familial fatal parkinsonism with cortical sparing. Kimura D, et al. Can J Neurol Sei 1987 


\section{BEHAVIOR \& PHYSIOLOGY}

Nov;14(4):597-9

+ The psychological development of a twin: a case study of the importance of a symptom. MacLean G, et al. Can J Psychiatry 1987 Oct;32(7):588-94

+ Assessing sex differences in neonatal survival: a study of discordant twins. Berman SM, et al. Int J Epidemiol 1987 Sep; $16(3): 436-40$

+ Stability of the type A structured interview and related questionnaires in a 10-year follow-up of an adult cohort of twins. Carmelli $D$, et al. J Behav Med 1987 Oct:10(5):513-25

+ A twin study of the psychiatric side effects of oral contraceptives. Kendler KS, et al.

J Nerv Ment Dis 1988 Mar; 176(3):153-60

Gilles de la Tourette's syndrome in monozygotic twins [letter] Vieregge $P$. J Neurol Neurosurg Psychiatry 1987 Nov; 50(11):1554-6

+ Shared genes, shared experiences, and similarity of personality: data from 14,288 adult Finnish co-twins. Rose RJ, et al. J Pers Soc Psychol 1988 Jan;54(1):161-71

+ Psychiatric genetics and psychiatric nosology. Zerbin-Rüdin E. J Psychiatr Res 1987; 21(4):377-83 (49 ref.)

† Sampling problems in twin research. Torgersen S. J Psychiatr Res 1987;21(4):385-90

$\dagger$ The relationship of twinning to the familial-sporadic distinction in schizophrenia. Reveley AM, et al. J Psychiatr Res 1987; 21(4):515-20

$\dagger$ Respiratory distress syndrome in second-born versus first-born twins. A matched case-control analysis. Arnold C, et al. N Engl J Med 1987 Oct $29 ; 317(18): 1121-5$

$\dagger$ Evidence for a genetic aetiology in reading disability of twins. DeFries JC, et al. Nature 1987 Oct 8-14;329(6139):537-9

$\uparrow$ Prediction of discordant twins using ultrasound measurement of biparietal diameter and abdominal perimeter. Brown $C E$, et al. Obstet Gynecol 1987 Nov;70(5):677-81

$\dagger$ Effect of birth order on intraventricular hemorrhage in very low birth weight twins. Pearlman SA, et al. Obstet Gynecol $1988 \mathrm{Mar}$; 71(3 Pt 1):358-60

MMPI study of identical twins: cancer patients and bone marrow donors. Friedrich WN, et al. Psychol Rep 1987 Aug;61(1):127-30

$\dagger$ indicates that an abstract appears with the citation in the author section. 


\section{GENETIC TRAITS \& METHODS}

+ Constrained maximum likelihood analysis of familial resemblance of twins and their parents. Boomsma DI, et al.

Acte Genet Med Gemellol (Roma) 1987, 36(1):29-39

+ The analysis of marital interaction in cross-sectional twin data. Heath AC. Acta Genet Med Gemellol (Roma) 1987; 36(1):41-9

+ Prospects for detecting genotype $X$ environment interactions in twins with breast cancer. Martin NG, et al. Acta Genet Med Gemellol (Roma) 1987;36(1):5-20

+ Spectral analysis of twin time series designs. Molenaar PC, et al.

Acta Genet Med Gemellol (Roma) 1987; 36(1):31-9

New frontiers of gemellology. Gedda $L$. Acta Genet Med Gemellol (Roma) 1987;36(1): 1-4 (0 ref.)

+ Family history and birthweight in monozygotic twins concordant and discordant for psychosis Lewis SW, et al.

Acta Genet Med Gemellol (Roma) 1987 36(2):267-73

+ Speech and language development in preschool twins. Hay DA, et al.

Act Genet Med Gemellol (Romn) 1987. 36(2):213-23

+ Growth characteristics in twins and higher order multiple births. Buckler JM, et al. Acta Genet Med Gemellol (Roma) 1987; 36(2): 197-208

+ Multivariate analysis of genetic and environmental influences for longitudinal height and weight data. Fischbein $S$, et al.

Acta Genet Med Gemellol (Roma) 1987; 36(2):171-80

$\dagger$ Nature-nurture interaction in different types of school environments. A longitudinal study. Fischbein S

Acts Genet Med Gemellol (Roma) 1987; $36(2): 155-63$

$\dagger$ Genetic factors in open-angle (simple and capsular) glaucoma. A population-based twin study. Teikari JM. Acta Ophthalmol (Copenh) 1987 Dec;65(6):715-20

+ Primary open-angle glaucoma in 2 monozygotic twin pairs. Teikari $\mathrm{JM}$, et al.

Acts Ophthalmol (Copenh) 1987 Oct.65(5):607-11

Necrotizing enterocolitis in multiple gestation [letter] Goldman HI. Am J Dis Child 1987 Dec; 141(12):1252-3

$+\mathbf{X}$-linked $\mathrm{m} r$ ntal retardation with marfanoid habitus. Fryns JP, et al. Am J Med Genet 1987 Oct:28(2):267-74 (4 ref.)

† Incidental finding of double minutes (DM), single minutes (SM), homogenously staining regions (HSR), premature chromosome condensation (PCC), and premature centromere division (PCD)? Bühler EM, et al. Ann Genet (Paris) 1987;30(2):75-9

+ Secular trend of twin concordance in late fetal death. Terrenato $L$, et al. Ann Hum Genet 1986 Jan;50 ( Pt 1):63-8

+ Sinus histiocytosis with massive lymphadenopathy. Occurrence in identical twins with retroperitoneal disease. Marsh WL Jr, et al. Arch Pathol Lab Med 1988 Mar: 112(3):298-301

Testing genetic models for multiple symptoms: an application to the genetic analysis of liability to depression. Eaves LJ, et al. Behav Genet 1987
Jul; 17(4):331-41

Genetic and environmental factors in primary dysmenorrhea and its relationship to anxiety, depression, and neuroticism. Silberg JL, et al. Behav Genet 1987 Jul;17(4):363-83

Prenatal diagnosis in twin pregnancies. Hager JM, et al. Birth Defects 1987;23(6):95-9

Incidence of the premenstrual syndrome in twins. Dalton K, et al. Br Med J [Clin Res] 1987 Oct 24;295(6605): 1027-8

+ A set of monozygotic twins with Rett syndrome. Coleman M, et al. Brain Dev 1987;9(5):475-8

+ Attentional and perseverative impairment in two cases of familial fatal parkinsonism with cortical sparing. Kimura D, et al. Can J Neurol Sci 1987 Nov; 14(4):597-9

+ The psychological development of a twin: a case study of the importance of a symptom. MacLean G, et al. Can J Psychintry 1987 Oct;32(7):588-94 The association of Peyronie's disease with HLA B7 cross-reactive antigens. A case report of identical twins. Ziegelbaum $M$, et al Cleve Clin J Med 1987 Sep-Oct;54(5):427-30

+ The relative roles of genetic and environmental factors in the regulation of erythrocyte C3b receptor (ECR1) numbers in normal individuals. Fyfe A, et al. Clin Exp Immunol 1987 Oct: $70(1): 231-7$

+ Microcephalic osteodysplastic dwarfism (type II-like) in siblings. Verloes A, et al. Clin Genet 1987 Aug:32(2):88-94

$\uparrow$ Concordance for type 2 (non-insulin-dependent) diabetes mellitus in male twins. Newman $B$, et al. Diabetologia 1987 Oct;30(10):763-8

+ Epilepsy with primarily generalized myoclonic-astatic seizures: a genetically determined disease. Doose $\mathrm{H}$, et al. Eur J Pediatr 1987 Nov; 146(6):550_-

+ Plasma cholesterol variation in the National Heart, Lung and Blood Institute Twin Study. Christian JC, et al. Genet Epidemiol 1987;4(6):433-46 (41 ref.)

+ Twin studies in multiple sclerosis. Heltberg A.

Ital J Neurol Sci 1987 Jun:Suppl 6:35-9

Melasma occurring in twin sisters [letter] Hughes BR. J Am Acad Dermatol 1987 Nov:17(5 P 1):841

Solid facial edema as a complication of acne vulgaris in twins [letter] Tosti A, et al. J Am Acad Dermatol 1987 Nov;17(5 Pt 1):843-4

+ Stability of the type A structured interview and related questionnaires in a 10-year follow-up of an adult cohort of twins. Carmelli $D$, et al. J Behav Med 1987 Oct:10(5):513-25

+ Familial aggregation of congenital dislocation of the hip in a Norwegian population. Kramer AA, et al. J Clin Epidemiol 1988;41(1):91-6 Genetic studies in twins. Grim CE.

3 Clin Hypertens 1987 Sep;3(3 Suppl):74S-78S

+ Trisomy 13 in monozygotic twins discordant for major congenital anomalies. Naor $\mathbf{N}$, et al. J Med Genet 1987 Aug;24(8):500-2

† Goldenhar syndrome and overlapping dysplasias, in vitro fertilisation and ovopathy. Jongbloet PH. J Med Genet 1987 Oct:24(10):616-20

IVF and Goldenhar syndrome [letter] Yovich J, et al. J Med Genet 1987 Oct;24(10):644

+ Spastic paraplegia associated with brachydactyly and cone shaped epiphyses. Fitzsimmons JS, et al. J Med Genet 1987 Nov;24(11):702-5

+ A twin study of the psychiatric side effects of oral contraceptives. Kendler KS, et al. J Nerv Ment Dis 1988 Mar; 176(3):153-60

+ indicates that an abstract appears with the citation in the author section. 


\section{GENETIC TRAITS \& METHODS}

Gilles de la Tourette's syndrome in monozygotic twins [letter] Vieregge P.

J Neurol Neurosurg Psychiatry 1987 Nov; 50(11):1554-6

† Identical twins with malrotation and type IV

jejunal atresia. Olson LM, et al.

J Pediatr Surg 1987 Nov;22(11):1015-6

$\dagger$ Shared genes, shared experiences, and similarity of personality: data from 14,288 adult Finnish co-twins. Rose RJ, et al. J Pers Soc Psychol $1988 \mathrm{Jan} ; 54(1): 161-71$

$\dagger$ Psychiatric genetics and psychiatric nosology. Zerbin-Ritdin E. J Psychiatr Res 1987; 21(4):377-83 (49 ref.)

$\dagger$ Sampling problems in twin research. Torgersen

S. J Psychiatr Res 1987;21(4):385-90

$\dagger$ The relationship of twinning to the

familial-sporadic distinction in schizophrenia.

Reveley AM, et al. J Psychiatr Res 1987; 21(4):515-20

Gilbert's syndrome in identical twins [letter] Graham JR. Med J Aust 1987 Nov 16; 147(10):524

$\dagger$ Evidence for a genetic aetiology in reading disability of twins. DeFries JC, et al. Nature 1987 Oct 8-14;329(6139):537-9

+ Multiple sclerosis in a nationwide series of twins. Kinnunen E, et al. Neurology 1987 Oct; 37(10):1627-9

Genetic analysis of Kawasaki disease. Sasazuki T, et al. Prog Clin Biol Res 1987;250:251-5

MMPI study of identical twins: cancer patients and bone marrow donors. Friedrich WN, et al. Psychol Rep 1987 Aug;61(1):127-30

+ indicates that an abstract appears with the citation in the author section. 


\section{OBSTETRICS \& PEDIATRICS}

+ Birthweight differences, the transfusion syndrome and the cognitive development of monozygotic twins. O'Brien PJ, et al.

Acta Genet Med Gemellol (Roma) 1987; 36(2):181-96 (46 ref.)

+ Growth characteristics in twins and higher order multiple births. Buckler JM, et al.

Acta Genet Med Gemellol (Roma) 1987; 36(2):197-208

+ The expectation and parentage of twins. A study on the language development of twin infants. Alin-Akerman B.

Acta Genet Med Gemellol (Roma) 1987; 36(2):225-32

+ Dominance and submissiveness between twins. 1 . Perinatal and development aspects. Moilanen I. Acta Genet Med Gemellol (Roma) 1987; $36(2): 249-55$

+ Family history and birthweight in monozygotic twins concordant and discordant for psychosis. Lewis SW, et al.

Acta Genet Med Gemellol (Roma) 1987; $36(2): 267-73$

+ Immature cervical teratoma arising in one fetus of a twin pregnancy. Case report and review of the literature. Hitchcock $A$, et al.

Acta Obstet Gynecol Scand 1987;66(4):377-9 (4 ref.)

+ Routine hospital care does not improve prognosis in twin gestation. Rydhström $\mathbf{H}$, et al. Acta Obstet Gynecol Scand 1987;66(4):361-4 Conjoined twins in triplet pregnancy [letter] Shalev E, et al. Am J Obstet Gynecol 1987 Nov; 157(5):1323

$\dagger$ The length of the human umbilical cord in twin pregnancies. Soernes $T$, et al.

Am J Obstet Gynecol 1987 Nov;157(5):1229-30

$\dagger$ Antenatal diagnosis and management of monoamniotic twins. Rodis $\mathbf{J F}$, et al.

Am J Obstet Gynecol 1987 Nov; 157(5):1255-7

$\dagger$ Endocrine response to selective embryocide in a gonadotropin-induced quintuplet pregnancy. O'Keane JA, et al. Am J Obstet Gynecol 1988 Feb;158(2):364-7

+ Management of quintuplet pregnancy by selective embryocide. Farquharson DF, et al. Am J Obstet Gynecol 1988 Feb;158(2):413-6

† Prenatal sonographic diagnosis and management of a twin pregnancy with placenta previa and hemicardia. Seeds JW, et al. Am J Perinatol 1987 Oct:4(4):313-6

+ Secular trend of twin concordance in late fetal death. Terrenato L, et al. Ann Hum Genet 1986 Jan;50 ( Pt 1):63-8

Selective termination in the first trimester [letter] Wass D, et al. Aust N Z J Obstet Gynaecol 1987 May; $27(2): 171-2$

Genetic and environmental factors in primary dysmenorrhea and its relationship to anxiety, depression, and neuroticism. Silberg JL, et al. Behav Genet 1987 Jul;17(4):363-83

Prenatal diagnosis in twin pregnancies. Hager JM, et al. Birth Defects 1987;23(6):95-9

$\dagger$ Yield and nutrient content of milk in eight women breast-feeding twins and one woman breast-feeding triplets. Saint $L$, et al. Br J Nutr 1986 Jul;56(1):49-58

Incidence of the premenstrual syndrome in twins. Dalton K, et al. Br Med J [Clin Res] 1987 Oct 24:295(6605): 1027-8

+ Brainstem auditory evoked responses alteration in twin neonates. Delorme C, et al. Brain Dev 1987; 9(3):319-20

+ indicates that an abstract appears with the citation in the author section. $\uparrow$ Cord entanglement in monoamniotic twin pregnancies. Lyndrup $J$, et al Eur J Obstet Gynecol Reprod Biol 1987 Nov; 26(3):275-8

+ Multiple pregnancy after in-vitro fertilization and embryo transfer: report of a quadruplet pregnancy and delivery. Goldman JA, et al. Hum Reprod 1987 Aug;2(6):511-5

$\dagger$ Assessing sex differences in neonatal survival: a study of discordant twins. Berman SM, et al. Int J Epidemiol 1987 Sep;16(3):436-40

$\dagger$ Intravenous nutrition during a twin pregnancy. Karamatsu JT, et al.

JPEN J Parenter Enteral Nutr 1987 Sep-Oct: 11(5):499-501

$\dagger$ Prediction of discordant twins using ultrasound measurement of biparietal diameter and abdominal perimeter. Brown $\mathrm{CE}$, et al. Obstet Gynecol 1987 Nov;70(5):677-81

† Internal podalic version with unruptured membranes for the second twin in transverse lie. Rabinovici J, et al. Obstet Gynecol $1988 \mathrm{Mar}$ 71(3 Pt 1):428-30

$\uparrow$ Triplet pregnancy with delivery on three separate days. Cardweil MS, et al. Obstet Gynecol 1988 Mar;71(3 Pt 2):448-9

$\dagger$ Deceased co-twin as a cause of false positive amniotic fluid AFP and AChE. Winsor EJ, et al. Prenat Diagn 1987 Sep;7(7):485-9

+ Biamnial elevated alpha-fetoprotein and positive acetylcholinesterase in twins, one with anencephaly. Holbrook RH JR, et al. Prenat Diagn 1987 Nov;7(9):653-5 


\section{GENERAL}

† The Vietnam Era Twin (VET) Registry: method of construction. Eisen $S$, et al. Acta Genet Med Gemellol (Roma) 1987; $36(1): 61-6$

Growth hormone deficiency in one of identical twins. Surtees RA, et al. Acta Paediatr Scand 1987 Sep; $76(5): 837-8$

+ Maximum oxygen uptake and cardiac size and function in twins. Fagard $R$, et al. Am J Cardiol 1987 Dec 1;60(16):1362-7

t Congenital Pelger-Huet anomaly in triplets. Ware $R$, et al. Am J Hematol 1988 Mar;27(3):226-7

† Goldenhar complex in discordant monozygotic twins: a case report and review of the literature Boles DJ, et al. Am J Med Genet 1987 Sep; 28(1):103-9 (36 ref.)

Lessons from conjoined twins. Machin GA, et al. Am J Med Genet 1987 Sep;28(1):89-97

Monozygosity and holoprosencephaly: cleavage disorders of the 'midline field'. Suslak $L$, et al. Am J Med Genet 1987 Sep;28(1):99-102

$\uparrow$ Positioning of separated conjoined twins with scoliosis/lordosis. Belcher MA.

Am J Occup Ther 1987 May;41(5):329-32

Unusual ocular findings in multicystic encephalomalacia. Fiore PM, et al.

Am J Ophthalmol 1987 Oct $15 ; 104(4): 436-7$

† Suxamethonium apnoea in a 4-month-old twin. Mehta Y, et al. Anaesthesia 1987 Aug; 42(8):868-70

Perioperative management of conjoined twins. Diaz JH, et al. Anesthesiology 1987 Dec; 67(6):965-73 (44 ref.)

+ Craniofacial morphology and occlusal variation in monozygous and dizygous twins. Lobb WK. Angle Orthod 1987 Jul;57(3):219-33

Congenital anomalies in twins. Bryan E, et al. Baillieres Clin Obstet Gynaecol 1987 Sep; 1(3):697-721 (159 ref.)

Vicarious analgesia? [letter] Finnegan PJ. Br Dent J 1987 Sep 5;163(5):144

+ Conjoined twins, right atrial isomerism, and sequential segmental analysis. Rossi $\mathrm{MB}$, et al. Br Heart J 1987 Nov;58(5):518-24

Hand dermatitis and contact sensitivity in twins. Tosti A, et al. Contact Dermatitis 1987 Aug; 17(2):113-4

† Modular transport ventilation system for twins. Belgaumkar TK, et al. Crit Care Med 1987 Dec; 15(12):1131-2

A case of conjoined twins, with a brief historical review. Aynalem G. Ethiop Med J 1988 Jan; 26(1):41-4

$\dagger$ Total peroxidase deficiency in eosinophils: a report on twin sisters, one with a refractory anaemia. Lepelley P, et al. Eur J Haematol 1987 Jul; 39(1):77-81

Bacillus Alcaligenes fecalis septicemia and meningitis in the newborn. Kishan $J$, et al.

Indian J Pediatr 1987 Sep-Oct;54(5):789-90

Zygosity of twin births [letter] Kumar A

Indian Pediatr 1987 Feb;24(2):178-9

$\dagger$ Genetic influence on the serum levels of naturally occurring human IgG antibodies to dietary antigens. Quantitative assessment from a twin study. Husby S, et al. J Immunogenet 1987 Apr-Jun;14(2-3):131-42

$\dagger$ Immunologic studies in identical twins concordant for juvenile rheumatoid arthritis but discordant for monoclonal gammopathy and amyloidosis. Husby G, et al. J Lab Clin Med 1988 Mar; 111(3):307-14

No association between griseofulvin and conjoined twinning [letter] Knudsen LB

Lancet 1987 Nov 7;2(8567):1097

Treatment of Langerhans cell histiocytosis with alpha-interferon [letter] Jakobson AM, et al.

Lancet 1987 Dec 26:2(8574):1520-1

Haemoglobin levels in pregnancy in mothers whose infants died subsequently of sudden infant death syndrome [letter] Beal SM. Med J Aust 1987 Sep 7;147(5):257-8

$\dagger$ Craniopagi: anatomical characteristics and classification. Winston KR. Neurosurgery 1987 Dec;21(6):769-81 (122 ref,)

† Surgical division of craniopagi. Winston KR, et al. Neurosurgery $1987 \mathrm{Dec} ; 21(6): 782-91$ (57 ref.)

+ Improved estimates of discordance ratios in twin studies. Franti CE, et al. Stat Med 1987 Dec; 6(8):961-70

+ Acardiac fetus in a triplet pregnancy. Landy $\mathrm{HJ}$ et al. Teratology 1988 Jan;37(1):1-6 


\section{AUTHOR SECTION}

\section{A}

Aberg A see Rydhutrö̀n H

Abo $\mathbf{K}$ see Kinnumen $\mathbf{E}$

Airakginen PJ see Telkari JM

Alfier A, Gatti I, Alferi AC: Weight and height growth in twins and children born in the last decade. Acta Genet Med Gemellol (Roma) 1987; 36(2):209-11

Weight and height growth has been examined in 400 twins and 229 singletons born 1975-1985. Periodical measurements have been taken from 0 to 7 years of age. As compared to values obtained in a previous study of twins and singletons born 1960-1974, though limited to the first year of age, twins appear to continue to do worse than singletons in their growth. However, height values appear to have become higher in the first year of age in both twins and singletons born 1975-1985.

Alfieri AC see Alfieri $A$

Alin-Akerman B: The expectation and parentage of twins. A study on the language development of twin infants. Acta Genet Med Gemellol (Roma) 1987; 36(2):225-32

This is a follow-up study aiming to describe personality development of twins and possible differences at different ages. The investigation was conducted at the Mother Clinic in the Karolinska Hospital in Stockholm. This report describes the language development of 35 twin pairs at 9 months of age. The development values show that no greater differences exist for girls between twins and singletons. The language result is however lower. The boys, on the other hand, have considerably lower results both on total development scale and on the language scale.

Amery A see Fagord R

Amir $\mathbf{Y}$ see Neor $\mathbf{N}$

Andernon RH see Rossi MB

Arnold C, McLean FH, Kramer MS, Usher RH: Respiratory distress syndrome in second-born versus first-born twins. A matched case-control analysis. N Engl J Med 1987 Oct 29;317(18):1121-5

The well-known increased risk of the respiratory distress syndrome in a twin born second as compared with the twin born first is usually attributed to the second twin's predisposition to depression at birth ('asphyxia'). We analyzed the etiologic roles of birth order, presentation, and depression at birth in the development of the respiratory distress syndrome in matched case-control populations drawn from 221 preterm twin pairs. Among the 39 twin pairs discordant for respiratory distress syndrome, the second twin was the affected member in 31 pairs. Second birth order was the only independent risk factor, but only in vaginal deliveries (matched odds ratio, 14.2; 95 percent confidence interval, 2.5 to 81.1). Second twins delivered abdominally did not have an increased risk relative to first twins (odds ratio, 0.9; confidence interval, 0 to 17.8 ). When depression at birth was evaluated as an outcome variable, malpresentation, rather than birth order, was the major risk factor (independent matched odds ratios of 2.7 [confidence interval, 1.0 to 7.5 ] and 1.3 [0.7 to 2.5$]$, respectively). Thus, second twins' increased risk of respiratory distress syndrome cannot be explained by a predisposition to depression at birth; a more important factor may be that second twins do not benefit from the salutary effects of labor to the same extent as first twins.

Achkeand J see Goldman JA

Aynalen G: A case of conjoined twins, with a brief historical review. Ethiop Med J 1988 Jan;26(1):41-4

\section{B}

Baier WK see Doose $H$

Baker CL see Cardwell MS

Bakke $T$ see Soernes $T$

Bakker P: Autonomous languages of twins. Acta Genet Med Gemellol (Roma) 1987;36(2):233-8 Twins are regularly reported to invent languages of their own, unintelligible to others. These languages are known as autonomous languages, cryptophasia or idioglossia. Despite current belief, this is not a rare phenomenon. Autonomous languages exist in about $40 \%$ of all twins, but often disappear soon. In this study, nine autonomous languages are compared: the circumstances in which they emerge, how these languages relate to the parents' language (the model language) and how they are structured. The prototypical situation is one in which two or more close siblings (not necessarily twins) grow up closely together during the language acquisition period. If an adult model language is frequently absent, the children use each other as a model and acquire the language imperfectly. The language may stabilise at that level. If a model is completely absent, the children probably do not create a language. In all cases known, the language consists of onomatopoeic expressions, some invented words, but for the greatest part of words from the adult language adopted to the constrained

phonological possibilities of young children. These words being hardly recognizable, the language may turn out to be completely unintelligible to speakers of the model languages, but they resemble each other in that they lack morphology and that word order is based on pragmatic principles such as saliency and the semantic scope of words. Neither the structure of the languages nor its emergence can be explained by other than situational factors.

Baldwin VJ see Farquharson DF

Barkai G see Rabinovici J

Barnett HJ see Kimura D

Batton DG see Pearlman SA

Beal SM: Haemoglobin levels in pregnancy in mothers whose infants died subsequently of sudden infant death syndrome [letter] Med J Aust 1987 Sep 7; 147(5):257-8

Belcher MA: Positioning of separated conjoined twins with scoliosis/lordosis. Am J Occup Ther 1987 May; 41(5):329-32

Infantile scoliosis has a potential for progression. This paper discusses the use of a soft material to correct scoliosis in a medically stable, at-risk infant It illustrates that early intervention is desirable in preventing the progression of the lateral curve of the trunk. It also illustrates that the three-point positioning principle can be effective with soft materials with an infant. Foam rubber blocks were used to apply pressure at three strategic points, the shoulder, the hip, and the convex curve on an infant's trunk. At the age of 7 months the infant was able to move herself into a normal position with good head and body alignment.

Belgaumkar TK, Patrick NB, Gorman RR: Modular transport ventilation system for twins.

Crit Care Med 1987 Dec;15(12):1131-2

A single modular transport ventilation system has been modified for ventilation of twins by duplicating the gas supply lines, gas blender, and ventilator. This twin ventilator system can be assembled easily in minutes, has essential built-in safety features, and 


\section{AUTHOR SECTION}

provides simultaneous yet individualized ventilation support to each infant during transport without the need for additional personnel.

Bennett $M$ see Wass $D$

Berg $K$ see Kramer AA

Berman SM, Binkin NJ, Hogue CJ: Assessing sex differences in neonatal survival: a study of discordant twins. Int J Epidemiol 1987 Sep;16(3):436-40

We identified 1699 liveborn twin pairs, discordant for sex. In this study, which essentially controls for gestational age, race, and maternal risk factors among males and females, there was no significant sex difference (108 male deaths and 103 female deaths) in neonatal mortality ( $\mathrm{p}$ greater than 0.50 ). However, there was a sex difference in intrauterine growth, since $53 \%$ of the males, but only $42 \%$ of the females had birthweights greater than 2499 grams $(p=0.0002)$. A differential growth pattern can bias birthweight-specific assessments of survival. Such a bias may have been responsible for our finding that low-birthweight white females had better survival than did males in that category, since there was no such sex difference found among white twins born prematurely (greater than 36 weeks gestation). Therefore, we recommend that accurate assessments of sex differences in neonatal survival should be on the basis of gestational age, controlling for race and maternal risk factors.

Bettoli $V$ see Tosti $A$

Beutler $\mathbf{C}$ see Bühler EM

Bias $\mathbf{W}$ see Coleman $\mathbf{M}$

Bielen $E$ see Fagard $\mathbf{R}$

Binkin NJ see Berman SM

Bodurtha J see Boles DJ

Boklage CE: Twinning, nonrighthandedness, and fusion malformations: evidence for heritable causal elements held in common. Am J Med Genet 1987 Sep;28(1):67-84 (113 ref.)

Certain relatively common congenital malformations that are reported to be excessive in frequency among twins are also found in excess among first-degree relatives of twins. They are familially associated with each other. Like twinning, they are familially associated with nonrighthandedness (NRH). They also share the fact that they affect structures that are built by the fusion of bilateral embryonic halves and then remodeled under the influence of neural crest mesenchyme. This conjunction of associations suggests that twinning, NRH, and the fusion malformations share causal elements, some of which may be heritable. Determination of spatial relationships in embryogenesis ("embryonic body symmetry determination') and the functions of neural crest mesenchyme may be mechanisms unifying these effects.

Boklage CE: Developmental differences between singletons and twins in distributions of dental diameter asymmetries. Am J Phys Anthropol 1987 Nov; 74(3):319-31

Craniofacial development and behavioral development differs between human twins and singletons in several ways which are related to symmetry development and detectable in adults. In most of those ways, twin zygosity groups do not differ. Here we use distributions of dental diameters, as a model subsystem of craniofacial development, to show that twins, of both zygosities and both sexes, are substantially more symmetrical than singletons. The observed differences are consistent with previous related observations, none of which can readily be explained by any consequence of twin gestation. They seem instead to represent peculiarities of developmental biology familially associated with twinning.

Boles DJ, Bodurtha J, Nance WE: Goldenhar complex in discordant monozygotic twins: a case report and review of the literature. Am J Med Genet 1987 Sep; 28(1):103-9 (36 ref.)

In 1952, Goldenhar described a pair of monozygotic twins who were discordant for epibulbar dermoids, auricular appendages, malformations of the auricle, and hemifacial microsomia. Eighteen twin pairs have subsequently been described in which at least one member exhibited these manifestations. We report on an additional pair of discordant dichorionic monozygotic male twins. All of the 5 monozygotic twin pairs for which placental information is available have been discordant and 2 of these had dichorionic membranes. The failure of discordant monozygotic twins to be limited to monochorionic pairs argues against the hypothesis that developmental abnormalities arising from the placental vascular anastomoses that are commonly found in monozygotic twins is the probable explanation for the discordant expression of these traits in twins.

Bonelli U see Tosti A

Boomsma DI, Molensar PC: Constrained maximum likelihood analysis of familial resemblance of twins and their parents.

Acta Genet Med Gemellol (Roma) 1987;36(1):29-39 When the univariate twin design is extended by including parents of twins, it is possible to assess additive genetic effects in the presence of assortative mating and genotype-environment correlation, the effects of parental influence, as well as the extent of residual shared environmental influences. The analysis of data obtained in such an extended twin design can be carried out by means of constrained maximum likelihood confirmatory factor analysis. Specifically, the structural model underlying this design can be represented as a LISREL model with nonlinear constraints. This representation offers the possibility to consider extended multivariate twin designs involving common genetic and environmental factors. The proposed method will be illustrated with applications to simulated and real data.

Boomsma DI see Molenaar PC

Borhani NO see Christian JC

Boyd AT see Karamatsu JT

Brazy J see Ware R

Brown BS see Winsor EJ

Brown CE, Guzick DS, Leveno KJ, Santos-Ramos R, Whalley PJ: Prediction of discordant twins using ultrasound measurement of biparietal diameter and abdominal perimeter. Obstet Gynecol 1987 Nov; 70(5):677-8i

Prediction of twin birth weight discordancy was tested in 116 gestations using sonographic measurements of biparietal diameter (BPD) and abdominal perimeter. Abdominal perimeter measurement differences of $20 \mathrm{~mm}$ or greater were more sensitive and specific than BPD difference in detecting twins with dissimilar birth weights.

Bryan E, Little J, Burn J: Congenital anomalies in twins. Baillieres Clin Obstet Gynaecol 1987 Sep; 1(3):697-721 (159 ref.)

Buckler JB see Buckler JM

Buckler JM, Buckler JB: Growth characteristics in twins and higher order multiple births.

Acta Genet Med Gemellol (Roma) 1987; 36(2):197-208

Measurements of height and weight have been undertaken on 201 pairs of twins and 46 sets of higher multiples once each at various ages through 


\section{AUTHOR SECTION}

childhood. The heights of twins are comparable to the overal] population of singletons, those of higher multiples are slightly undersized. However, the total group of twins were shorter than expected when compared with the heights of parents and siblings, but this was entirely accounted for by that component of the group who at birth had been very light for dates. The children in all groups of multiples were underweight for their height in comparison with standards of a comparable population and with their own siblings.

Bühler EM, Fessler R, Bentler C, Gargano G: Incidental finding of double minutes (DM), single minutes (SM), homogenously staining regions (HSR), premature chromosome condensation (PCC), and premature centromere division (PCD)? Ann Genet (Paris) 1987;30(2):75-9

The incidental finding of DM's, minutes, HSR's, PCC, and PCD in two completely unrelated cases-one is a prenatal diagnosis in a twin pregnancy complicated by hydramnios and feto-fetal exsanguination, the other is an adult Klinefelter patient--raises the question whether such findings are coincidental or whether there is a common denominator in such cases. Possible relationships between these phenomena and the observed cases are discussed.

Burn J see Bryan E

Burn J see Road MB

Buttiens M see Fryns JP

\section{C}

\author{
Campbell WA see Rodis JF \\ Cangemi FE see Flore PM \\ Caple $\mathbf{P}$ see Cardwell MS \\ Cardwell MS, Caple P, Baker CL: Triplet pregnancy \\ with delivery on three separate days. \\ Obstet Gynecol 1988 Mar;71(3 Pt 2):448-9 \\ Obstetric complicatione of triplet pregnancies may \\ make the delivery of extremely premature infants \\ in these multiple gestations inevitable. To our \\ knowledge, this case represents the first report of \\ triplets delivered on three separate days, 16 days \\ apart, using the technique of delayed interval \\ delivery. One of the infants survived. \\ Carmelli D, Rowenman RH, Cheaney MA: Stability of \\ the type A structured interview and related \\ questionnaires in a 10-year follow-up of an adult \\ cohort of twins. J Behav Med 1987 Oct; $10(5): 513-25$ \\ Associations between initial and 10-year follow-up \\ assessment of the Type A behavior pattern (TABP) \\ were examined in a sample of adult male twins using \\ a brosd range of inatruments. When assessment is \\ made by the Structured Interview and limited to \\ the dichotomous Types A and B rating, 67\% of the \\ subjects received the same rating on both occasions. \\ Spearman rank correlations between repeated \\ self-report measures of TABP ranged from .55 to \\ .70 . Overall the stability among the self-report \\ measures was greater than between the self-reports \\ and the Structured Interview. Utilizing the twin \\ design the relationship of genetic and environmental \\ factors to tracking of TABP was examined and \\ compared between monozygotic and dizygotic twin \\ pairs. The implication of these results to the TABP \\ construct is discussed. \\ Cantelli WP see Curitian JC \\ Cromer MA see Carmelli D \\ Chithere B see Lewh SW \\ Chrition JC, Borhad NO, Castelli WP, Fabaitz R, \\ Norton JA Jr, Reed T, Rowenman R, Wood PD, Yu
}

PL: Plasma cholesterol variation in the National Heart, Lung and Blood Institute Twin Study. Genet Epidemiol 1987;4(6):433-46 (41 ref.) Plasma cholesterol was measured in the fifth decade of the life of 249 pairs of monozygotic (MZ) and 262 pairs of dizygotic (DZ) World War II veteran twins and $70 \%$ of the same cohort 10 years later. There were no significant differences between the mean cholesterol values for $\mathrm{MZ}$ and $\mathrm{DZ}$ twins, and the within $D Z$ pair mean squares were significantly larger than the within $\mathrm{MZ}$ pair mean squares for all of the cholesterol variables measured. However, the $D Z$ twins were found to have greater total variance, positive skewness, and leptokurtosis than the $M Z$ twins for total and high-density lipoprotein cholesterol, and the total/high-density ratio. Comparisons with published data revealed that the variance of $\mathrm{DZ}$ twins was similar to that of singletons while the $M Z$ twins have smaller total variance, perhaps owing to a missing component of variation. Hypotheses for the source of the differences in the zygosity distributions are proposed including environmental influences (pre- or post-natal and within- or among-families), genetic differences, and selection at the time of induction into the armed services. Because of the differences in total variance of the two zygosities it is difficult to know which estimates of genetic variance or heritability have the least bias. However, these data provide clues that may lead to further understanding of sources of plasma cholesterol variation that could be important to the future understanding of risk for coronary heart disease.

\section{Cohen $T$ see Naor $N$}

Coleman M, Naidu S, Murphy M, Pines M, Bias W: A set of monozygotic twins with Rett syndrome. Brain Dev 1987;9(5):475-8

The case history of a set of twins with Rett syndrome is presented. The twins test as monozygotic by both blood groups and HLA titers. In a previous generation, the family had three females who died of an unknown degenerative disease on the paternal side of this family. The discussion includes a hypothesis about female genetic disease occurring in a recessive pattern on the $X$ chromosome.

Collet L see Delorme C

Collett $S$ see Hay DA

Colwell KA see Friedrich WN

Cooke J see Karamatsu JT

Cosson A see Lepelley $\mathbf{P}$

Cronin RJ see Husby $\mathbf{G}$

\section{$\mathbf{D}$}

Dalton K, Dalton $M E$, Guthrie $\mathrm{K}$ : Incidence of the premenstrual syndrome in twins.

Br Med J [Clin Res] 1987 Oct 24;295(6605):1027-8

Dalton $\mathbf{M E}$ see Dalton $\mathbf{K}$

Davidson $\mathbf{S}$ see Naor $\mathbf{N}$

Davis AK see Friedrich WN

Davis SL, Tooley WH, Hunt JV: Developmental outcome following posthemorrhagic hydrocephalus in preterm infants. Comparison of twins discordant for hydrocephalus. Am J Dis Child 1987 Nov; 141(1i): $1170-4$

The mental development and neurologic outcome of four sets of preterm twins, in whom one infant within each pair developed posthemorrhagic hydrocephalus during the neonatal period, were assessed. Each hydrocephalic infant presented with signs of increased intracranial pressure and required placement of a ventriculoperitoneal shunt. Three of 


\section{AUTHOR SECTION}

the four hydrocephalic infants required revision or replacement of the shunt during the first year. The four nonhydrocephalic infants had normal neurologic outcomes. All four hydrocephalic infants had some neurologic abnormalities on follow-up examination. Neurologic abnormalities were transient in one infant and persistent in three others, each of whom showed evidence of mild right hemiparesis. Within each twin pair, developmental rates and mental test scores were strikingly similar throughout infancy and early childhood. Two of the twin pairs have undergone psychological assessments at 8 and 11 years of age. Relatively lower IQ scores were obtained for the hydrocephalic child in each twin pair at these ages.

Deaton JL see Rodis JF

DeFries JC, Fulker DW, LaBuda MC: Evidence for a genetic aetiology in reading disability of twins. Nature 1987 Oct 8-14;329(6139):537-9

Reading disability (dyslexia) is a major social, educational, and mental health problem. Although estimates of prevalence vary, up to $10-15 \%$ of school-age children have severe reading deficits in spite of average intelligence and adequate educational opportunity. That reading disability may have a constitutional basis has long been recognized, and results of twin and family studies suggest that one or more of its forms may be heritable; however, definitive evidence for a genetic aetiology has not been reported. Establishing a heritable basis for reading disability could suggest possible causes, give improved risk estimates, facilitate early diagnosis, and provide validity tests for ostensible subtypes. In this report, we apply a recently developed multiple regression analysis to data collected from a sample of 64 pairs of identical twins and 55 pairs of fraternal twins, in which at least one member of the pairs is reading disabled, and present evidence for a significant genetic aetiology.

Delorme C, Collet L, Soares I, Morgon A, Salle B: Brainstem auditory evoked responses alteration in twin neonates. Brain Dev 1987;9(3):319-20

The authors obtained BAER recordings for 20 premature twins and 20 premature non-twins. The two groups were comparable as to conceptional age (36-37 weeks), gestational age, chronological age, birthweight, sex ratio and head size. The results showed a prolongation of the central conduction time (I-V interval) in the premature twins. This may be due to the intra-uterine growth retardation of twins.

Desposito F see Suslak L

Devine WA see Rossi MA

Diaz JH, Furman EB: Perioperative management of conjoined twins. Anesthesiology 1987 Dec; 67(6):965-73 (44 ref.)

Dicker D see Goldman JA

Doose H, Baier WK: Epilepsy with primarily generalized myoclonic-astatic seizures: a genetically determined disease. Eur J Pediatr 1987 Nov; 146(6):550-4

This paper presents case reports of patients suffering from myoclonic-astatic and stimulus-sensitive myoclonic seizures, respectively. It gives details of clinical and EEG data in the pertinent families. This is discussed in the context of controversial nosographic concepts of epilepsies with myoclonic seizures, and of the results of extensive family investigations. The findings demonstrate the decisive importance of hereditary factors in the pathogenesis of myoclonic and myoclonic-astatic epilepsy, the genetic background of which is probably polygenic.

\section{E}

Eaves LJ, Martin NG, Heath AC, Kendler KS: Testing genetic models for multiple symptoms: an application to the genetic analysis of liability to depression. Behav Genet 1987 Jul; 17(4):331-41

Eaves LJ see Kendler KS

Eaves LJ see Martin NG

Eisen S, True W, Goldberg J, Henderson W, Robinette CD: The Vietnam Era Twin (VET) Registry: method of construction.

Acta Genet Med Gemellol (Roma) 1987;36(1):61-6 A Vietnam Era (1964-1975) Twin Registry of American male-male veterans born between 1939 and 1955 has been developed to provide a study sample for research evaluating the impact of Vietnam service on the medical and psychosocial aspects of health. In preparation for developing the Registry, several alternative sources of twins and methods for identifying twins were investigated. A computerized database of veterans discharged from the military after 1967 was selected as the source because it contains about $50 \%$ of the total Vietnam era veteran population, is reasonably unbiased, and provides a feasible method for identifying twins. Twins were identified using an algorithm which involved matching entries on the database for same last name, different first name, same date of birth, and similar social security number. Twin status was confirmed by review of military records. The registry, now complete, is composed of 7,400 twin pairs. It will be an important resource for future research projects.

Eisen $\mathbf{S}$ see Goldberg $\mathbf{J}$

Elzouki AY see Kishan J

Epstein LG see Fiore PM

Esrachi A see Guttman R

Essig YP see Hager JM

Estienne MH see Lepelley $P$

\section{$\mathbf{F}$}

Fabsitz R see Christian JC

Fabsitz $R$ see Newman $B$

Fagard R, Van Den Broeke C, Bielen E, Amery A: Maximum oxygen uptake and cardiac size and function in twins. Am J Cardiol 1987 Dec 1; 60(16): $1362-7$

The contribution of heredity to the interindividual variability of maximum oxygen uptake and of cardiac size and function of healthy male twins, age 18 to 31 years, was studied to evaluate the role of the heart in the inheritance of aerobic power. Twelve pairs of monozygotic and 12 pairs of dizygotic twins were examined. Weight ( $p$ less than 0.05 ), relative weight (Quetelet index) ( $p$ less than 0.01) and skinfold thickness ( $p$ less than 0.01 ) were found to be genetically determined, as well as heart rate at rest (p less than 0.05) and systolic blood pressure (p less than 0.05). Genetic variation was significant ( $p$ less than 0.05 ) both for absolute and for weight-adjusted oxygen uptake, measured at peak exercise on the bicycle ergometer. However, the influence of inheritance on aerobic power was not associated with a significant genetic effect on the end-diastolic left ventricular internal diameter or on its fractional shortening as assessed by echocardiography. Genetic variation had a significant ( $p$ less than 0.05 ) effect on left ventricular mass, but this could be attributed to the inheritance of body size. These data indicate that cardiac factors are not significantly involved in the inheritance of aerobic power and suggest that 


\section{AUTHOR SECTION}

cardiac hypertrophy in athletes is secondary to training.

Falletta JM see Ware $R$

Farmelo MJ see Heger JM

Farquharson DF, Wittmenn BK, Hansmann M, Yuen BH, Baldwin $V J$, Lindahl S: Management of quintuplet pregnancy by selective embryocide.

Am J Obstet Gynecol 1988 Feb;158(2):413-6

Selective embryocide was performed as a two-stage procedure in a patient with a quintuplet pregnancy in the first trimester. No complications occurred, and the patient was delivered of healthy twins at term. This procedure may be offered to selected patients with pregnancies with greater than five embryos.

Farquharion DF see O'Keane JA

Fefer A see Friedrich WN

Feldberg D see Goldman JA

Fenaux $P$ see Lepelley $P$

Ferguson JE 2d see Holbrook RH JR

Fessler $\mathbf{R}$ see Bühler EM

Finnegan PJ: Vicarious analgesia? [letter]

Br Dent J 1987 Sep 5;163(5):144

Fiore PM, Cangemi FE, Epstein LG: Unusual ocular findings in multicystic encephalomalacia.

Am J Ophthalmol 1987 Oct 15;104(4):436-7

Fischbein S, Pedersen NL: Multivariate analysis of genetic and environmental influences for longitudinal height and weight data.

Acta Genet Med Gemellol (Roma) 1987; 36(2):171-80

A multivariate analysis of genetic and environmental influences on longitudinal height and weight data from a Swedish twin sample is presented. For height in boys, genetic correlations of all ages with the first time point decrease during puberty and increase afterwards. A more linear pattern is evident for the girls. For weight in boys, genetic and environmental correlations are similar to the ones for height.

Genetic correlations for girls are stable with age, while environmental correlations peak at 13.5 years and decrease drastically thereafter. The patterns for height and weight in boys suggest that a new set of genes may be turned on during puberty and turned off again afterwards. The pattern found for weight in girls indicates that a simple additive genetic model is not appropriate. It is necessary, however, to apply the model to actual data from several time points to recognize the inadequacy of the model.

Fischbein S: Nature-nurture interaction in different types of school environments. A longitudinal study. Acta Genet Med Gemellol (Roma) 1987; 36(2): 155-63

A model of nature-nurture interaction in school situations emanating from a longitudinal Swedish twin project is presented. This model implies that interactional effects measured by MZ-DZ

within-pair comparisons over time are related to the type of behavior studied, as well as teacher and pupil influences at different levels. In a more permissive and stimulating school situation, hereditary factors are hypothesized to be more influential (decisive for behavioral variation) than in a more restrictive and nonstimulating situation. A study of such interactional effects will require longitudinal measurements of pupil behavior as well as teacher and parental influences. To acquire a variation in permissiveness/restrictiveness and

stimulation/nonstimulation at the societal level, comparisons are made between twins attending grade 4-6 in compulsory schools in Sweden and twins of the same age attending Israelian Kibbutz schools.

Fitadimason JS, Guilbert PR: Spastic parapiegia associated with brachydactyly and cone shaped epiphyses. J Med Genet 1987 Nov;24(11):702-5 Male uniovular twins presented at the age of 20 years with spastic paraplegia which had been slowly progressing over the years. Both have skeletal anomalies of their hands and feet with brachydactyly, cone shaped epiphyses, and an abnormal metaphyseal phalangeal pattern profile. In addition, they have a non-specific dysarthria and low-normal intellectual ability.

Flom LS see Olson LM

Forrest $P$ see Short TG

Franti CE, Wiggins AD, Kraus JF: Improved estimates of discordance ratios in twin studies. Stat Med 1987 Dec;6(8):961-70

In the study of monozygotic twins relative to disease and risk factors, particular interest focuses on the subset who are discordant for some suspected risk factor (for example, smoking), since such twins constitute a natural case-control pair. In such studies, questionnaires designed to identify the status of all twin pairs are sometimes error prone and can yield misleading estimates of the

concordance-discordance ratios. Greater efforts to verify the characteristics of apparently discordant pairs than to verify those of apparently concordant pairs can result in the 'unequal ascertainment' fallacy. Using the results of a questionnaire with known error rates and the 'apparent' frequencies yielded, we present unbiased, maximum likelihood estimates of the 'true' proportions of concordant and discordant pairs. concordant and discordant pairs. We also present approximate covariances among these estimates.

Friedman GD see Newman B

Friedrich WN, Smith CK, Harrison SD, Colwell KA, Davis AK, Fefer A: MMPI study of identical twins: cancer patients and bone marrow donors. Psychol Rep 1987 Aug;61(1):127-30

Fryns JP, Buttiens M: X-linked mental retardation with marfanoid habitus. Am J Med Genet 1987 Oct; 28(2):267-74 (4 ref.)

Here we report on two pairs of mildly to moderately mentally retarded brothers with marfanoid habitus and similar craniofacial changes. They had a long and narrow face, small mandible, high-arched palate, and hypernasal voice, as previously reported by Lujan et al (Am J Med Genet 17:311-322, 1984) in four mentally retarded males of a large kindred. The present data suggest the existence of a specific type of $\mathrm{X}$-linked mental retardation with marfanoid habitus.

Fulker DW see DeFries JC

Fumia $\mathbf{F}$ see Rodis JF

Furman EB see Diaz JH

Fyfe A, Holme ER, McKay IC, Zoma A, Hunter J, Lucie NP, Whaley $\mathbf{K}$ : The relative roles of genetic and environmental factors in the regulation of erythrocyte C3b receptor (ECR1) numbers in normal individuals. Clin Exp Immunol 1987 Oct; 70(1):231-7

Erythrocyte C3b receptors (ECR1) have been measured in 122 pairs of twins (60 monozygotic, 62 dizygotic) using an [125I]-labelled monoclona] antibody (E11). The range of ECR1 numbers was wide, 99-4179 sites/cell, with a log-normal distribution around a geometric mean of 837 sites/cell. The intra-pair variance in dizygotic twins was no greater than that in monozygotic twins. These data indicate that ECR I numerical expression is governed by environmental rather than genetic factors. 


\section{AUTHOR SECTION}

\section{G}

Galletly DC see Short TG

Gargano G see Bühler EM

Garrett $W$ see Wass $D$

Gatti I see Alfieri A

Gedda L: New frontiers of gemellology.

Acta Genet Med Gemellol (Roma) 1987;36(1):1-4 (0 ref.)

Goldberg J, True W, Eisen S, Henderson W, Robinette CD: The Vietnam Era Twin (VET) Registry: ascertainment bias.

Acta Genet Med Gemellol (Roma) 1987;36(1):67-78

An examination of ascertainment bias in

identification of twin pairs in the Vietnam Era Twin

Registry has been conducted. A complete listing of all male-male Vietnam era veteran twin pairs born in Connecticut between 1939 and 1955 was obtained $(\mathbf{N}=150)$. An attempt was made to match these pairs with a listing of Vietnam era veteran twin pairs derived from the United States Department of Defense's Defense Manpower Data Center (DMDC) computer files. The results indicate that the DMDC files identified only $46.7 \%$ of the 150 Connecticut born Vietnam era veteran pairs. Statistically significant differences ( $P$ less than 0.05 ) between pairs found on the DMDC files and Connecticut veteran pairs missing from the DMDC files are observed for the following variables: a) year of discharge from military service, b) total length of active military service, c) branch of service, and d) foreign service. No consistent pattern of bias is observed for factors related to the physical and psychosocial health of veteran pairs. The implications of the ascertainment biases in the Vietnam Era Twin Registry are discussed.

Goldberg $\mathbf{J}$ see Eisen $\mathbf{S}$

Goldman HI: Necrotizing enterocolitis in multiple gestation [letter] Am J Dis Child 1987 Dec; 141(12):1252-3

Goldman JA, Feldberg D, Ashkenaxi J, Shelef $\mathbf{M}$, Dicker D, Hart J: Multiple pregnancy after in-vitro fertilization and embryo transfer: report of a quadruplet pregnancy and delivery. Hum Reprod 1987 Aug:2(6):511-5

The first baby from in-vitro fertilization (IVF) was born in England in 1978 as a result of retrieval of a single preovulatory oocyte in the course of a natural cycle (Steptoe and Edwards, 1978). At present most programmes of IVF throughout the world do not use natural cycles producing only one oocyte, but rather multiple oocyte cycles produced by clomiphene citrate (CC), human menopausal gonadotrophin (HMG), or pure follicle stimulating hormone (FSH), either separately or in combination, sequentially or concomitantly, for the induction of multiple follicular maturation.

Gorman RR see Belgaumkar TK

Graham JR: Gilbert's syndrome in identical twins [letter] Med J Aust 1987 Nov 16;147(10):524

Grennert L see Rydhström H

Grim CE: Genetic studies in twins.

J Clin Hypertens 1987 Sep;3(3 Suppi):74S-78S

Guerra L see Tosti A

Guilbert PR see Fitzsimmons JS

Guthrie $\mathbf{K}$ see Dalton $K$

Guttman R, Nathan M, Esrachi A:

Restrictiveness-permissiveness of their environment as perceived by kibbutz twins and singletons.

Acta Genet Med Gemellol (Roma) 1987; $36(2): 165-70$

This research compares similarities and differences between kibbutz twins and singletons on individual perceptions of extent of restriction imposed by their fathers and mothers, teachers, caretakers and peers with regard to the children's choices, plans, and actual activities. During the past two years, the parents of all kibbutz twins in Israel of age 1 to 18 have been contacted. They provided background information about themseives and their twin children. In each kibbutz, two control singletons were selected of the same sex and age for each twin pair, yielding a 'quartet'. With the aid of a mapping sentence, questionnaires were constructed to help ascertain the child's role in life areas such as family, friendship, school, hobbies, work, amusement. Questionnaires with the same facet design are being administered to children (twin and singleton), mothers, fathers, teachers, and caretakers. In addition, each child is given a battery of tests--including the verbal WISC, Block Design, Raven Matrices, and Reading Comprehension. The children will be interviewed and tested in three successive years, beginning either in grade 4 or 5 . Data will thus be obtained on changes in perception of permissiveness-restrictiveness and their relation to performance at ages 9 to 13 . To date 9-year-olds in 14 kibbutzim have been interviewed. Analyses of responses to four questions are presented in this paper. The preliminary analyses indicate that twins and singletons have similar means and distributions with regard to the extent to which the children feel they are told what to do by either parent.

Guzick DS see Brown CE

\section{$\mathbf{H}$}

Hagberg $H$ see Jakobson AM

Hager JM, Tedesco TA, Rattan PK, Knuppel RA, Miller KI, Farmelo MJ, Essig YP: Prenatal diagnosis in twin pregnancies. Birth Defects 1987;23(6):95-9

Hahn A see Kimura D

Handelsman D see Kendler KS

Hansmann $M$ see Farquharson DF

Harada $F$ see Sasazuki T

Harlan DM see Marsh WL Jr

Harrison SD see Friedrich WN

Hart J see Goldman JA

Hartmann PE see Saint $L$

Hay DA, O'Brien PJ: Early influences on the school social adjustment of twins.

Acta Genet Med Gemeliol (Roma) 1987; 36(2):239-48

The birth of twins is often accompanied by complications which may affect both twins equally (eg, prematurity) or which may establish differences between the twins (eg, one coming home from hospital first). Parents' ratings of behaviour may reflect and even perpetuate the influence of such variables and it is of interest to see if people less familiar with the twins' history can observe any long-term effects. In the La Trobe Twin Study teachers routinely complete the Bristol Social Adjustment Guide, an assessment of social maladjustment in children aged 5-16 years. Extreme prematurity and problems at delivery were generally associated with the Underreaction syndrome--the child who is unforthcoming, withdrawn and depressed. Withdrawal, depression and maladaptive behaviour to classroom peers were much more common among those twins discharged from hospital after the cotwin. A major mediating factor was that the parents admitted to greatly preferring the one to come home first. These raise questions 


\section{AUTHOR SECTION}

both about the practice of bringing twins home separately (which occurred in $21 \%$ of the cases) and about intervening variables in studies of personality and temperament.

Hay DA, Prior M, Collett S, Williams M: Speech and language development in preschool twins.

Acta Genet Med Gemellol (Roma) 1987. 36(2):213-23

While language, articulation and reading problems have been well documented in young twins, it is not clear how extensive such problems can be or how early in childhood they become evident. At the age of 30 months, twin boys in the La Trobe Twin Study were 8 months behind matched singletons and twin girls on expressive language and 6 months behind on verbal comprehension. They were also 5 months behind on symbolic play and this delay was closely related to language. 'Secret' language characterised most of the twin boys but not the giris and the relation of this to articulation delays is discussed. To examine if exposure to other children helps the twin boys, 38-53 month old twins and singletons were matched on the Columbia Mental Maturity Scale at the time of starting preschool. The twin boys had more articulation problems and all twins scored much lower on a Sociability questionnaire completed by the teacher. After 8 months at preschool, all children had advanced in Sociability, but the twins remained just as far behind with poor Sociability relating to poor articulation. The role of intervention programs is discussed.

\section{Hay DA see O'Brien PJ}

Heath AC: The analysis of marital interaction in cross-sectional twin data. Acta Genet Med Gemellol (Roma) 1987;36(1):41-9 The effects on twin data of social interaction between spouses is examined. When social interaction leads to an increase in marital resemblance (eg through reciprocal imitation), the variance of married individuals is increased, compared to the variance of unmarried individuals. Furthermore, the expected correlations between concordant married twin pairs will be lower than the expected correlations between concordant unmarried twin pairs, with the discordant twin correlations being intermediate in value. It is therefore possible, in principle, to detect the effects of marital interaction without using either longitudinal data or data on spouse pairs. However, to be detectable in twin data, marital interaction must be strong, or must exhibit marked asymmetry of effects between males and females. Genotype $x$ environment intera tion can also produce heterogeneity of coirelation between concordant married, discordant, and concordant unmarried twin pairs, when genetic and environmental effects interact with marital status. However, this will usually produce increased estimates of the genetic component of variance in unmarried twins, whereas marital interaction produces increased genetic variance in married twins.

Heath AC sec Eaves LJ

Heath AC see Kendler KS

Heath AC see Martin NG

Heath AC see Silberg JL

Heifetz SA see Winsor EJ

Hellkkilï K see Kaprio J

Heltberg A: Twin studies in multiple sclerosis. Ital J Neurol Sci 1987 Jun;Suppl 6:35-9

The classical method of evaluating whether genetic factors are involved in the etiology of a given disease and to what extent is the twin method. However, methodological problems are great, and it is possible only in a few countries to apply this method to multiple sclerosis (MS) research. To draw genetical conclusions it is of fundamental importance that the material should be an unselected, unbiased material derived from a twin population. Another

fundamental point is the diagnosis of twin zygosity. In MS research the twin method has been applied by several authors, but a Mendelian mode of inheritance has not been shown to exist. However, an association of MS to the genetic HLA system has been demonstrated, and this suggests that genetical factors are of some importance in the development of MS. Methodological problems are discussed and the most important twin studies in MS, including the Danish twin study.

Henderson $W$ see Eisen $S$

Henderson W see Goldberg J

Hennekens CH see Levine RS

Herbert WN see Seeds JW

Hitchcock A, Sears RT, O'Neill T: Immature cervical teratoma arising in one fetus of a twin pregnancy. Case report and review of the literature.

Acta Obstet Gynecol Scand 1987;66(4):377-9 (4 ref.) This is the first recorded case of an immature cervical teratoma arising in one fetus of a twin pregnancy. Although real-time ultrasound detected the presence of an abnormality, its true nature was not established until after histological examination. Extra-amniotic prostaglandin pregnancy termination was performed at 20 weeks' gestation due to the onset of acute hydramnios and the rapid increase in tumor size. Delivery of both fetuses was performed under general anesthesia. Extraction of the abnormal twin was only possible after the tumor was separated off from the fetal neck in utero.

Ho SY see Rossi MB

Hogue CJ see Berman SM

Holbrook RH JR, Krovoza AM, Schelley S, Ferguson JE 2d: Biamnial elevated alpha-fetoprotein and positive acetylcholinesterase in twins, one with anencephaly. Prenat Diagn 1987 Nov; $7(9): 653-5$ Anencephaly in twin B was accompanied by elevated amniotic fluid alpha-fetoprotein (AFP) and a positive acetylcholinesterase (AChE) band on gel electrophoresis in both twin sacs, although twin A was normal. AChE results did not help distinguish the false positive AFP in this set of twins, implying that AChE may diffuse transamniotically as has been previously postulated for AFP. In light of the low concordance rate for neural tube defects in twins, patient counselling in this situation must include the information that AFP and AChE may be falsely elevated in normal twin when the other twin has a neural tube defect.

Hole P see Mehta Y

Holme ER see Fyfe $A$

Hughes BR: Melasma occurring in twin sisters [letter] J Am Acad Dermatol 1987 Nov;17(5 Pt 1):841

Hunt JV see Davis SL

Hunter $\mathbf{J}$ see Fyfe $A$

Husby G, Williams RC Jr, Tung KS, Smith FE, Cronin $\mathbf{R J}$, Sletten $\mathbf{K}$, Westermark P: Immunologic studies in identical twins concordant for juvenile rheumatoid arthritis but discordant for monoclonal gammopathy and amyloidosis. J Lab Clin Med 1988 Mar;111(3):307-14

Identical twins concordant for juvenile rheumatoid arthritis but discordant for monoclonal gammopathy and amyloidosis were the subjects of a study done with mixed leukocyte culture, anti-idiotypic antisera against serum and urinary $M$ component from the amyloid-affected twin, and in vitro estimations of 


\section{AUTHOR SECTION}

M-component idiotype synthesis by peripheral blood mononuclear cells. Immunohistochemical analysis of renal amyloid deposits in the affected twin showed $A L$ amyloid of the lambda-II variable region subgroup. M-component idiotypes were confined only to the twin with serum and urine $M$ components.

Husby S, Schultz Larsen F, Petersen PH: Genetic influence on the serum levels of naturally occurring human IgG antibodies to dietary antigens. Quantitative assessment from a twin study. J Immunogenet 1987 Apr-Jun;14(2-3):131-42 Serum IgG antibodies to ovalbumin (OA) and beta-lactoglobulin (BLG) were quantified by ELISA techniques in 22 monozygotic (MZ) and 24 dizygotic (DZ) healthy twin pairs. Antibody levels were comparable in the $M Z$ and $D Z$ groups both for anti-OA and anti-BLG antibodies. The genetic variance (GWT) was 0.167 for $\log$ IgG anti-OA antibodies, and 0.173 for $\log \mathrm{IgG}$ anti-BLG antibodies, with heritability estimates of 0.44 and 0.37 , respectively. No indication was observed of genotype-environmental interaction or differential environmental covariance for the log antibody levels in the $M Z$ and $D Z$ twins. The anti-OA and anti-BLG antibody levels in the same individual correlated only to a low degree. The levels of naturally occurring serum IgG antibodies are significantly influenced by genetic factors.

\section{$\mathbf{J}$}

Jakobson AM, Kreuger A, Hagberg H, Sundström C: Treatment of Langerhans cell histiocytosis with alpha-interferon [letter] Lancet 1987 Dec 26; 2(8574):1520-1

Jesse MJ see Levine RS

Jones B see MacLean G

Jongbloet PH: Goldenhar syndrome and overlapping dysplasias, in vitro fertilisation and ovopathy.

J Med Genet 1987 Oct;24(10):616-20

In contrast to the opinion of Yovich et al, who documented Goldenhar syndrome in one of possibly monozygous twin brothers conceived by in vitro fertilisation and embryo transfer, I suggest that ovopathy is the cause of this anomaly. The eight criteria which have to be met before a condition can be said to be caused by overripeness ovopathy are shown to be satisfied. My conclusion remains that, in general, sporadically occurring Goldenhar variants, as distinct from familial cases, should be considered to be just casualities in the broad 'continuum of reproductive wastage' seen in high risk conceptions, one of which is IVF. This concept increases our understanding of human variation not satisfactorily explained by Mendelian inheritance.

\section{$\mathbf{K}$}

Kaprio J, Rose $R J$, Sarna $S$, Langinvainio $H$, Koskeavuo M, Rita H, Heikkill K: Design and sampling considerations, response rates, and representativeness in a Finnish Twin Family Study. Acta Genet Med Gemellol (Roma) 1987;36(1):79-93 Kinships composed of twin parents, their spouses and children, offer a robust and flexible sampling design for research in genetic epidemiology. Families-of-twins designs circumvent some of the sampling problems that arise when independent data sets are combined, and these designs provide unique evaluations of maternal influences, assortative mating and $\mathrm{X}$-linkage. Unfortunately, empirical studies of families of twin parents have been limited by relatively small samples and by the self-selection biases intrinsic in ascertainment of families from volunteer twin registries. A large and representative cohort of monozygotic and dizygotic twin parents, drawn from a population-based twin registry, provides the optimal sampling frame for twin-family research. This paper reviews the sampling considerations underlying the initial family study based on the Finnish Twin Cohort and evaluates the representativeness of the sampled twins. Spouses and adult children (over 18 years) of 236 pairs of twins, about equally divided by gender and zygosity, were evaluated by a postal questionnaire. Individual response rates exceeded $86 \%$ and in 464 of the 472 nuciear families (98.3\%), at last one member of the twin's family completed the questionnaire. The sampled twins, selected for fecundity to maximize statistical power of the obtained data, were broadly representative of non-selected twins drawn from the Cohort, with whom they were matched on age, gender, and zygosity. Such results suggest that the Finnish Cohort has excellent potential for extended twin-family research designs.

Kaprio J, Koskenvuo M, Langinvainio $H$, Romanov $K$, Sarna S, Rose RJ: Social and genetic influences on drinking patterns of adult men: a study of 5638 Finnish twin brothers. Alcohol Alcohol 1987; Supp1 1:373-7

Hierarchical multiple regression analyses of questionnaire data reported by male twins in the Finnish Twin Cohort were used to evaluate genetic and social influences on use and abuse of alcohol. The similarity in drinking patterns of twin brothers is related to the frequency of their social interaction, and monozygotic co-twins are in more frequent social contact. But the stepwise multiple regressions show that the greater social interaction of identical twins cannot account for their greater similarity in drinking patterns. We conclude that genetic variance significantly contributes to population variance in the frequency, quantity, and density of social drinking.

Kaprio $J$ see Kinnunen $E$

Kaprio J see Rose RJ

Kaprio $\mathbf{J}$ see Teikari JM

Karamatsu JT, Boyd AT, Cooke J, Vìnall PS, McMahon MJ: Intravenous nutrition during a twin pregnancy. JPEN J Parenter Enteral Nutr 1987 Sep-Oct;11(5):499-501

A case is reported of a woman in the third trimester of a twin pregnancy who required intravenous nutrition because of inadequate absorption of nutrients due to a jejunoileal bypass. Weight gain was poor, and there was evidence of intrauterine growth retardation before commencement of intravenous feeding. She received overnight intravenous nutrition for 6 weeks and gained weight with ultrasound evidence of fetal growth. During the 33rd week of gestation, she was delivered of healthy twin males who were at appropriate birth weights and development for their age of gestation. The considerations in intravenous nutrition for a twin pregnancy after jejunoileal bypass are discussed.

Kawasald $T$ see Sasazuki $T$

Kendler KS, Martin NG, Heath AC, Handelsman D, Eaves LJ: A twin study of the psychiatric side effects of oral contraceptives. J Nerv Ment Dis 1988 Mar; 176(3): $153-60$

Oral contraceptive (ORC)-related depression and irritability are among the most commonly reported drug-induced psychiatric symptoms. To investigate 


\section{AUTHOR SECTION}

the etiological role of genetic factors in ORC-related symptoms, we studied questionnaire responses in 715 monozygotic and $\$ 16$ dizygotic volunteer twin pairs concordant for ORC usage. Biometrical genetic analysis indicated that the liability to ORC-related depression was clearly influenced by genetic but not familial-environmental factors. Similar, but less definitive, results were found for ORC-related irritability. Multivariate genetic analysis indicated that both the genetic and the individual-specific environmental factors that influenced the liability to ORC-related depression and irritability were largely distinct from those that influence baseline levels of psychiatric symptoms. Genes play an important etiological role in ORC-related

psychiatric side effects. The genes that influence liability to these side effects appear to differ from those that are etiologically important in baseline

psychiatric symptomatology.

Kendler KS see Eaves LJ

Kent SG see Landy $H J$

Kierney CM see Olson LM

Kimura D, Hahn A, Barnett HJ: Attentional and perseverative impairment in two cases of familial fatal parkinsonism with cortical sparing.

Can J Neurol Sci 1987 Nov; 14(4):597-9

The neuropsychological findings in twin brothers with familial fatal Parkinsonism are reported.

Post-mortem examination had shown extensive pathology in basal ganglia and brainstem, but not in the cerebral cortex. Although both showed average intelligence three months prior to death, they had impairment on a sorting task and in seria attention span. Some possible neural mechanisms are discussed.

King MC see Newman B

Kinnunen E, Koskentuo M, Kaprio J, Aho K: Multiple sclerosis in a nationwide series of twins. Neurology 1987 Oct;37(10):1627-9

A nation wide Finnish Twin Cohort was linked with sickness insurance and hospital discharge registers on the basis of the unique identification number assigned to each Finnish citizen. The study series consisted of 4,063 monozygotic (MZ) and 9,001 dizygotic (DZ) same-sexed twin pairs born before 1958 and alive in 1981 . Altogether, 22 subjects representing $11 \mathrm{MZ}$ pairs and $10 \mathrm{DZ}$ pairs showed clinically definite multiple sclerosis (MS). In one MZ pair both members had the disease. The frequency of MS among DZ twins corresponded to the figure in the Finnish population, but the prevalence was higher in $M Z$ twins than in $D Z$ twins.

Kishan J, Elzouki AY, Mir NA: Bacillus Alcaligenes fecalis septicemia and men ngitis in the newborn. Indian J Pediatr 1087 Sep-Oet;54(5):789-90

Knudsen LB: No association between griseofulvin and conjoined twinning [letter] L ancet 1987 Nov 7 2(8567): 1097

Knuppel RA see Hager JM

Koskenvuo M see Kaprio

Koskenvuo $M$ see Kinnunen $E$

Koskenvuo $M$ see Rose RJ

Koskenvuo M see Teikari JM

Kramer AA, Berg K, Nance WE: Familial aggregation of congenital dislocation of the hip in a Norwegian population. J Clin Epidemiol 1988;41(1):91-6

Previous studies of congenital dislocation of the hip have not used adequate control groups in estimating the level of genetic influence on that trait

Furthermore, it could not be demonstrated that alleged maternal effects were not an artifact of reporting bias. To that end, information was obtained on the presence of the anomaly in the families of adult twins and their spouses participating in the Norwegian Twin Registry. The prevalence odds ratio for having that disorder in first degree relatives was 10.0. Stratifying by class of relatives, the prevalence odds ratio was 8.1 for fathers, 35.8 for mothers, 12.7 for siblings, and 3.3 for offspring. The increased prevalence odds ratio for mothers over that of fathers suggests a maternal effect. Since both males and females reported on the anomaly for each parental type, it is unlikely that the difference in prevalence odds ratios is due to general reporting bias.

Kramer MS see Arnold C

Kraus JF see Franti CE

Krenger A see Jakobson AM

Krovozs AM see Holbrook RH JR

Kumar A: Zygosity of twin births [letter]

Indian Pediatr 1987 Feb;24(2):178-9

Kurtzberg $\mathbf{J}$ see Ware $\mathbf{R}$

\section{L}

LaBuda MC see DeFries JC

Lambotte C see Verloes A

Lambrechts $L$ see Verloes A

Landy HJ, Larsen JW Jr, Schoen M, Larsen ME, Kent

SG, Weingold AB: Acardiac fetus in a triplet pregnancy. Teratology $1988 \mathrm{Jan} ; 37(1): \mathrm{I}-6$

The acardiac monster represents one of the most severe but rare congenital anomalies. It occurs only in multiple gestations associated with vascular anastomoses between the affected fetus and its co-twin. The prenatal diagnosis of an acardiac fetus must be suspected in any multiple gestation in which cardiac activity cannot be documented

sonographically in a growing fetus. We report an acardiac fetus occurring in a spontaneously conceived triplet pregnancy. A review of the literature, including pathogenetic theories and sonographic reports, is discussed.

Langinvainio $H$ see Kaprio $J$

Langinvainio $\mathbf{H}$ see Rose $\mathbf{R J}$

Larsen JW Jr see Landy $H J$

Larsen ME see Landy HJ

Lepelley P, Zandecki M, Paquet S, Lerche B, Estienne MH, Fensux P, Torpier G, Cosson A: Total peroxidase deficiency in eosinophils: a report on twin sisters, one with a refractory anaemia.

Eur J Haematol 1987 Jul;39(1):77-81

A total lack of EPO was fortuitously discovered in a 63-yr-old woman from the north of France who had primary refractory anaemia, but without dysgranulopoiesis; MPO activity was normal. Her twin sister, whose blood count was normal, also had EPO deficiency. This familial disorder was first described in the Israeli Jewish population and is very rare in Caucasians; it seems to have no pathological consequences. Microscopic studies showed no anomaly except a negativity of Sudan Black B staining which we consider to be a sign of peroxidase deficiency. Ultrastructural studies of the granules revealed normal cristalloid, but the matrix, which contains EPO in normal eosinophils, was very thin; the nature of the relation between functional and morphological anomalies has still to be elucidated.

Lerche $\mathbf{B}$ see Lepelley $\mathbf{P}$

Leveno $\mathbf{K J}$ see Brown CE

Levine RS, Hennekens CH, Jesse MJ: Genetic variance of weight and length in infant twins. Am J Epidemiol 1987 Nov;126(5):929-35 A population-based cohort of 166 twin pairs (67 monozygotic and 99 dizygotic) born at the Jackson 


\section{AUTHOR SECTION}

Memorial Hospital/University of Miami Medical Center, from July 1, 1976 to December 31, 1980 was identified. Body weight and length were measured at 14 days and at one, three, six, nine, and 12 months of age. Statistically significant genetic variance was found for both body weight and length at each data point. Heritability for body weight increased from 0.28 at 14 days to 0.64 at one year. Corresponding values for body length were 0.16 and 0.48 .

Lewis SW, Chitkara B, Reveley AM, Murray RM: Family history and birthweight in monozygotic twins concordant and discordant for psychosis.

Acta Genet Med Gemellol (Roma) 1987; 36(2):267-73

In a sample of monozygotic twins, intrapair differences in reported birthweight were larger in those pairs discordant for later psychosis, compared to pairs concordant for psychosis. A trend towards less family history of psychiatric disorder was also found in the discordant pairs.

Lindahl S see Farquharson DF

Little J see Bryan E

Lobb WK: Craniofacial morphology and occlusal variation in monozygous and dizygous twins. Angle Orthod 1987 Jul;57(3):219-33

A study of 60 pairs of twins, 30 monozygous and 30 dizygous, finding a strong genetic component overlaid by functional adaptation most prominent in the dental area.

Lucie NP see Fyfe A

Luther ER see Winsor E.

Lykken DT, MeGue M, Tellegen A: Recruitment bias in twin research: the rule of two-thirds reconsidered. Behav Genet 1987 Jul;17(4):343-62

Lyndrup J, Schouenborg L: Cord entanglement in monoamniotic twin pregnancies.

Eur J Obstet Gynecol Reprod Biol 1987 Nov; 26(3):275-8

Monoamniotic twin pregnancy involves a heavy risk of fatal umbilical cord entanglement. Two cases are reported. In the first case, both twins were found dead in the 36th week, and the monoamnionicity was recognized at birth. In the second case, the monoamnionicity was discovered during an ultrasound examination, and cord entanglement was suspected in the 35th week on the basis of a non-stress test (NST) with variable decelerations. Cesarean section was performed and two healthy children were delivered.

\section{$\mathbf{M}$}

McCarrick JP see Marah WL Jr

McGue $M$ see Lykken DT

Machin GA, Sperber GH: Lessons from conjoined twins. Am J Med Genet 1987 Sep;28(1):89-97

McKay IC see Fyfe A

McLean FH see Amold $C$

Maclean G, Jones B: The psychological development of a twin: a case study of the importance of a symptom. Can J Psychiatry 1987 Oct;32(7):588-94 In this paper we focus on the evaluation, assessment, diagnostic conclusions, and individual psychotherapy of a four year old twin who presented with the symptom of encopresis. Of great relevance to this boy is the literature concerning his vulnerability as a twin to develop symptomatology as he starts dealing with separation and individuation issues. Especially relevant are the multiple impacts of attitudes, perceptions and family rearing issues on the psychological development of this twin, and also on the development of this specific symptom choice--encopresis. Incorporating literature with case material, the meaning of the symptom of encopresis to this twin is discussed. The hypothesis defended is that the symptom enabled the twin to attract attention from his somewhat favoured brother, and to promote the process of separation and individuation from his parents and from his twin. It promoted his sense of himself as a separate and unique person in his own right. The child developed a sense of himself despite parental interference. With individual psychotherapy and family therapy, the need for the symptom was neglected.

McMahon MJ see Karamatsu JT

Magojore P see Saint L

Marsh WL Jr, MeCarrick JP, Harlan DM: Sinus histiocytosis with massive lymphadenopathy Occurrence in identical twins with retroperitoneal disease. Arch Pathol Lab Med 1988 Mar; 112(3):298-301

Sinus histiocytosis with massive lymphadenopathy (SHML) was originally defined as a relatively specific benign pseudolymphomatous disorder. Although the etiology remains unknown, the spectrum of SHML has been expanded to include predominance of extranodal disease in some patients, clinically significant immunologic abnormalities in $10 \%$ of patients, and fatal outcome in $7 \%$ of patients. We report the rare occurrence of SHML in identical twins; to our knowledge, SHML in identical twins has been reported only once previously. The two patients described are also unusual because of the predominance of retroperitoneal disease with minimal peripheral adenopathy. After a seven-year clinical course, one twin died of extensive retroperitoneal disease, liver failure, bleeding diathesis, and seizure disorder. The other twin is alive after a six-year course of progressive retroperitoneal disease.

Martin NG, Eaves LJ, Heath AC: Prospects for detecting genotype $\mathbf{X}$ environment interactions in twins with breast cancer.

Acta Genet Med Gemellol (Roma) 1987:36(1):5-20 We consider a study of $M Z$. and $D Z$ twin pairs ascertained because one or both twins have a disease. Genotypes at a major locus are known and putative environmental risk factors have been measured for all individuals. The power of the study to estimate the effect on liability of the measured and residual genetic and environmental effects $(\mathrm{Gm}, \mathrm{Gr}, \mathrm{Em}, \mathrm{Er})$ and all two-way interactions between them (except $\mathrm{Gr} X \mathrm{Er}$ ) is estimated by simulation. If liabilities can be indexed on a continuous scale ( $\mathrm{eg}$, blood pressure as an index of liability to hypertension), then a study of $600 \mathrm{MZ}$ and $600 \mathrm{DZ}$ pairs would have sufficient power to detect quite subtle interaction effects, even if ascertainment is greatly biased toward $M Z$ twins. If liabilities cannot be measured and only affection status is known, then the power of the study would be much lower, although not impracticably so. There appears to be no advantage in augmenting the twins with a sample of control individuals who have been drawn at random from the population regardiess of disease status, at least for the case we have considered in which the disease threshold on the liability scale is assumed to be known without error. The argument is developed in terms of the utility of the design for research into breast cancer.

Martin NG see Eaves LJ

Martin NG see Kendler KS

Martin NG soe Silbers J

Manhiach S see Rabinoviel J

Matheny AP Jr: Developmental research of twin's temperament. Acta Genet Med Gemellol (Roma) 


\section{AUTHOR SECTION}

1987;36(2):135-43

In the Louisville Twin Study, pairs of 3- and 4-year-old twins were provided with standardized competitive or cooperative tasks in a laboratory setting. Some tasks required a pair of twins to share toys; other fostered a more competitive engagement between the twins. Behavioral ratings identified temperament and social components at both ages, and between the two ages, there were

transformations in the links between the components. Parental ratings of the twins' temperament at the same ages were moderately correlated with the laboratory observations, but the pattern of the relations changed from one age to the next. The combined sets of measures were subjected to twin analyses for 43 pairs of twins. The results are discussed in terms of the similarity of $M Z$ and $D Z$ pairs for the dimensions of temperament and the transformations of temperament.

Matson P see Yovich J

Mehts Y, Hole P: Suxamethonium apnoea in a 4-month-old twin. Anaesthesia 1987 Aug; 42(8):868-70

A case of one infant of twins who developed suxamethonium apnoea is described. Investigation of the family revealed him to be homozygous for atypical cholinesterase while the other twin was normal. Tissue HLA and blood typing indicated the twins to be identical

Melino $M$ see Tosti $A$

Milier KL see Hager JM

Mimms GM see Suslak L

Mir NA see Kishan J

Mollanen I: Dominance and submissiveness between twins. I. Perinatal and development aspects.

Acta Genet Med Gemellol (Roma) 1987; 36(2):249-55

Factors predicting dominance and submissiveness between twins were analyzed in a longitudinal study of 234 twin pairs. Boys were found to be physically dominating, while the girls more often were psychically dominating and in the role of the spokesman. Low birth weight, to be second born, or low Apgar score tended to predict submissiveness, but not significantly. The same was true concerning perinatal asphyxia and hypoglycemia, which also showed some potential cumulative effect when occurring simultaneously. Those having developed faster or with higher intelligence were more often the leaders of the twin pair. Probably good neonatal care in modern hospitals tends to prevent perinatal damage, and therefore the previous findings of second born or small birth weight twins being most submissive was $n$ t fully established.

Moilanen I: Dominance and submissiveness between twins. II. Consequences for mental health. Acta Genet Med Gemellol (Roma) 1987; 36(2):257-65

In a follow-up study of 234 twin pairs, now aged $12-20 \mathrm{yrs}$, the intertwin relationships were evaluated by the parents and the twins themselves. The dominance-submissiveness aspect was inquired from three separate points of view, physical dominance, psychic dominance, and role of the spokesman. These three different aspects of dominance reflected on the twins' well being and mental health in somewhat different ways. The submissiveness in one area was often compensated by equality or dominance in another area, with only about $10 \%$ of adolescents being submissive or dominant in all three areas. According to the parents' reports, the most submissive twins suffered most often from psychosomatic symptoms, and the most dominant ones from nervous symptoms. The twins who themselves reported to be most submissive had most often somatic complaints and scored highest in the Kovacs' Depression Inventory.

Molenaar PC, Boomsma DI: Spectral analysis of twin time series designs.

Acta Genet Med Gemellol (Roma) 1987;36(1):51-9 The genetic analysis of physiological time series has to accommodate the presence of autocorrelation. This can be accomplished by means of orthogonal transformation of the series, thus enabling the use of standard genetic analysis techniques for the sequence of uncorrelated transforms. In view of the oscillatory character which typifies various physiological time series, it is customary to invoke spectral techniques for the analysis of these series. It can be shown that spectral analysis is an orthogonal transformation that asymptotically resembles principal component analysis.

Consequently, standard genetic analysis methods for the uncorrelated spectral transforms may be used. This approach will be illustrated with simulated and real (heart rate) data for univariate twin time series. Furthermore, it will be indicated that the proposed analysis can be readily generalized to multivariate time series.

Molenaar PC see Boomsma DI

Morgon A see Delorme C

Mulcahy $M$ see Yovich $J$

Mulliken JB see Winston KR

Murphy $\mathbf{M}$ see Coleman $\mathbf{M}$

Murray JE see Winston KR

Murray RM see Lewis SW

\section{$\mathbf{N}$}

Naidu $S$ see Coleman $M$

Nance WE see Boles DJ

Nance WE see Kramer AA

Naor N, Amir Y, Cohen T, Davidson S: Trisomy 13 in monozygotic twins discordant for major congenital anomalies. J Med Genet 1987 Aug; 24(8):500-2

The occurrence of trisomy 13 in twins is very rare. We report a pair of genotypically identical twins with trisomy 13 discordant for major anomalies. This case contributes to the already published data on the contribution of non-genetic factors to the aetiology of congenital malformations in monozygotic twins.

Nathan $M$ see Guttman $R$

Newman B, Selby JV, King MC, Slemenda C, Fabsitz $R$, Friedman GD: Concordance for type 2 (non-insulin-dependent) diabetes mellitus in male twins. Diabetologia 1987 Oct;30(10):763-8

Concordance for Type 2 (non-insulin-dependent) diabetes was determined in 250 monozygotic and 264 dizygotic white male twin pairs who participated in the National Heart, Lung, and Blood Institute Twin Study. These twins were born between 1917 and 1927 and were identified from military records without regard to disease status. We examined surviving members of the cohort twice-at mean ages of 47 and 57 years--and obtained 1-h post-load glucose tests and medication histories. Diagnostic criteria for Type 2 diabetes included a glucose value greater than or equal to $13.9 \mathrm{mmol} / /$ or current use of antidiabetic medication; possible Type 1 (insulin-dependent) diabetic twins were excluded. A strong genetic predisposition to Type 2 diabetes was suggested by 3 lines of evidence from the second examination: (1) $58 \%$ of monozygotic co-twins of 


\section{AUTHOR SECTION}

diabetic twins were themselves diabetic compared with an expected prevalence of $10 \%$; (2) only 1 of 15 originally disease-discordant, monozygotic twin pairs remained discordant for diabetes; and (3) $65 \%$ of non-diabetic monozygotic co-twins of diabetic twins had elevated glucose values. Because concordance for diabetes was less than $100 \%$ for twins aged 52-65 years and because twins varied in age at onset of disease, non-genetic factors may also influence diabetes development. Among the 19 monozygotic twins pairs discordant for diabetes, diabetic twins did not differ from their non-diabetic co-twins in obesity, diet, alcohol consumption, or education. However, compared with unrelated non-diabetic twins of the same ages, non-diabetic co-twins of diabetic twins gained more weight as adults ( $p$ less than 0.02) and had higher glucose levels (p less than 0.03).

Nochimson DJ see Rodis JF

Nordensköld F see Rydhström $\mathbf{H}$

Norton JA Jr see Christian JC

Novelletto A see Terrenato $L$

\section{$\mathbf{0}$}

O'Brien PJ, Hay DA: Birthweight differences, the transfusion syndrome and the cognitive development of monozygotic twins.

Acta Genet Med Gemellol (Roma) 1987; 36(2):181-96 (46 ref.)

Monochorionic twins may differ from dichorionic monozygotic (MZ) twins because of the transfusion syndrome and the timing of the cleavage of the zygote. Intrapair birthweight differences may be an indicator of these intrauterine variables. Previous evidence concerning weight differences and intellectual ability in $\mathrm{MZ}$ twins is reviewed with recommendations that future research also incorporates full placental data. Poorer scores on a nonverbal test are found for the lighter male twin of pairs with large intrapair differences in birthweight. Co-twin concordance rates for test scores are also highest for this group indicating that they vary consistently from other groups. Some evidence is presented from the present and earlier studies implicating anomalies of asymmetry or the transfusion syndrome as possible causes of these differences in brain functioning. The study adds further doubts as to the validity of any assumption of developmental equivalence between MZ twins and the general population.

O'Brien PJ see Hay DA

Ohrlander $\mathbf{S}$ see Rydhström $\mathbf{H}$

O'Keane JA, Yuen BH, Farquharson DF, Wittmann BK: Endocrine response to selective embryocide in a gonadotropin-induced quintuplet pregnancy. Am J Obstet Gynecol 1988 Feb;158(2):364-7

With the increase of medical induction of ovulation, the incidence of grand multiple pregnancy is becoming more frequent. We report the endocrine response of a quintuplet pregnancy that was reduced at 9 weeks' gestation to a twin pregnancy by selective embryocide and compared with quadruplet, triplet, and twin pregnancies. The human chorionic gonadotropin titer declined fourfold, but there were no clinically significant changes in the progesterone or estradiol levels. We conclude that, despite the drop in human chorionic gonadotropin, the placenta had attained adequate secretory maturation to prevent any significant decline in progesterone and estradiol leveis, which demonstrates the efficacy of this procedure at this gestational age.
Olson LM, Flom LS, Klerney CM, Shermete DW: Identical twins with malrotation and type IV jejunal atresia. J Pediatr Surg 1987 Nov;22(11):1015-6 Identical twins are reported, who associated with maternal anaphylactic shock at 101/2 weeks gestation, acquired a type IV jejunal atresia with total absorption of the small bowel beyond the third portion of the duodenum and persistence of the most terminal length of ileum in the ileocolic artery in an apple peel configuration. Both infants survived a tapered jejunoileostomy and have undergone a successful transition to a regular diet. This accidental occurrence in two infants at the same time and in an idcntical fashion is a rare event.

O'Neill $\mathbf{T}$ see Hitcheock A

\section{$\mathbf{P}$}

Paquet $\mathbf{S}$ see Lepelley $\mathbf{P}$

Patrick NB see Belgaumkar TK

Pearlman SA, Batton DG: Effect of birth order on intraventricular hemorrhage in very low birth weight twins. Obstet Gynecol 1988 Mar;71(3 Pt 1):358-60

We evaluated the effect of birth order on the incidence and severity of intraventricular hemorrhage in 29 sets of very low birth weight twins $(1500 \mathrm{~g}$ or less). Intraventricular hemorrhage occurred in 55\% of first-presenting twins and $62 \%$ of second-presenting twins. The incidence of minor intraventricular hemorrhage (grades I and II) was $41 \%$ for first twins and $52 \%$ for second twins, whereas the incidence of major intraventricular hemorrhage (grades III and IV) was 14 and $10 \%$, respectively. None of these differences reached statistical significance. We conclude that birth order does not appear to have a major effect on the incidence or severity of intraventricular hemorrhage in very low birth weight twins.

Pedersen NL see Fischbein S

Petersen PH see Husby S

Pines $M$ see Coleman $M$

Price DA see Surtees RA

Prior M see Hay DA

\section{$\mathbf{R}$}

Rabinovici J, Barkai G, Reichman B, Serr DM, Mashiach S: Internal podalic version with unruptured membranes for the second twin in transverse lie. Obstet Gynecol 1988 Mar; 71(3 Pt 1):428-30

Internal podalic version of the second twin in transverse lie has usually been performed after first rupturing the membranes of the second amniotic sac. In a prospective study on internal podalic version with unruptured amniotic membranes, 11

second-born twins in transverse lie were successfully delivered, with good neonatal outcome and without birth injuries. From our experience, it appears that this modified technique, when used within the presented guidelines, offers a reasonable alternative for the safe delivery of the second twin.

Rattan PK see Hager JM

Reed T see Christion JC

Reichman B see Rabinorici J

Reveley AM, Reveley MA: The relationship of twinning to the familial-sporadic distinction in schizophrenia. J Psychiatr Res 1987;21(4):515-20 Cerebral ventricular enlargement in schizophrenia may occur more often in the absence of a family history of the disorder, suggesting that it is related 


\section{AUTHOR SECTION}

to some non-genetic component of aetiology. This paper shows the finding to be much more apparent in a group of twins than in a similar group of singletons. Previous studies have shown twins in general to have larger cerebral ventricles than non-twins; we suggest that it is the greater susceptibility of twins to obstetric complications that is responsible for both the larger cerebral ventricles found in normal twins, and the very marked increase in ventricular size found in family history negative schizophrenic twins. We go on to consider evidence relating to a possible increased susceptibility of twins to develop schizophrenia.

Reveley AM see Lewis SW

Reveley MA see Reveley AM

Richards DS see Seeds JW

Rita $H$ see Kaprio J

Robinette CD see Eisen S

Robinette CD see Goldberg J

Rockoff MA see Winston KR

Rodis JF, Vintzileos AM, Campbell WA, Deaton JL, Fumia F, Nochimson DJ: Antenatal diagnosis and management of monoamniotic twins.

Am J Obstet Gynecol 1987 Nov;157(5):1255-7

Double survival of monoamniotic twins is rare. Three consecutive cases in which double survival occurred are presented. Accurate antenatal

diagnosis, intensive fetal surveillance, and operative delivery should improve neonatal outcome.

Romanov $\mathbf{K}$ see Kaprio $\boldsymbol{J}$

Rose RJ, Koskenvuo M, Kaprio J, Sarna S, Langinvainio H: Shared genes, shared experiences, and similarity of personality: data from 14,288 adult Finnish co-twins. J Pers Soc Psychol 1988 Jan; 54(1):161-7!

Similarities for Extraversion (E) and Neuroticism (N) scale scores from the Eysenck Personality Inventory were evaluated in 7,144 adult twin pairs, drawn from the population-based Finnish Twin Cohort, as a function of the co-twins' genetic resemblance, gender, age, and the frequency of their social interaction with each other. To separate effects of shared genes from those of shared experience, we performed hierarchical multiple regressions of double-entry data matrices. Results establish the predictive significance of both genetic and experiential influences: Genetic effects remained significant when tested after the effects of social contact were first removed; conversely, for $\mathbf{N}$ scores, the effects of social contact remained significant when assessed after genetic influences were first removed. These findings establish genetic variance in major dimensions of adult personality but assign a significant role $t u$ common experience as well. The first finding constructively replicates reports by others; the second challenges the widespread assumption that shared experiences have a negligible impact on sibling similarity in adult personality.

Roae RJ see Kaprio J

Rosenman $\mathbf{R}$ see Christian JC

Rocenman RH see Carmelli D

Roen MB, Burn J, Ho SY, Thlene G, Devine WA Anderson RH: Conjoined twins, right atrial isomerism, and sequential segmental analysis. Br Heart J 1987 Nov;58(5):518-24

Three cases of twins conjoined across the chest were examined. In one set, one twin showed right atrial isomerism and the other showed the usual atrial arrangement. The other two sets showed the usual atrial arrangement in both twins. The associated cardiac anomalies were diverse, ranging from atrioventricular septal defects to absent atrioventricular connections. Sequential segmental analysis was used successfully in each case to classify the complex cardiac anomalies. The first step was the recognition of the atrial arrangement. This was easily achieved despite the complexity of the intracardiac morphology.

Rydhström H, Nordensköld F, Grennert L, Ohrlander S, Aberg A: Routine hospital care does not improve prognosis in twin gestation.

Acta Obstet Gynecol Scand 1987;66(4):361-4 The effects of routine hospital care in twin gestation were evaluated by comparing the gestational outcome in two neighbouring university departments in southern Sweden. In Malmö, $79 \%(175 / 223)$ of all women with a twin pregnancy were given routine hospital care between the 26-28th and 35th gestational week, whereas in Lund only $4 \%(16 / 409)$ received such treatment. Hospitalization averaged 9 weeks in Malmö, versus 2 weeks in Lund. We found no significant differences between the two areas regarding gestational length, birth weight, or perinatal mortality. This study indicates that routine hospital care does not improve the prognosis in twin gestation.

\section{$\mathbf{S}$}

Saint L, Maggiore P, Hartmann PE: Yield and nutrient content of milk in eight women breast-feeding twins and one woman breast-feeding triplets. $\mathrm{Br} \mathbf{J}$ Nutr 1986 Jul;56(1):49-58

1. The milk yield of eight mothers each breast-feeding twins was determined by test weighing the mothers. Milk yield was determined at $2,3,6,9$, and 12 months post partum; however, only one mother was studied at all these times. 2 . At 6 months post partum the milk yield for individual breasts of three mothers fully breast-feeding and four mothers partially breast-feeding their infants ranged from 0.84 to 2.16 $\mathrm{kg} / 24 \mathrm{~h}$ and 0.42 to $1.39 \mathrm{~kg} / 24 \mathrm{~h}$ respectively. The average frequency of breast-feeding for the mothers studied at 6 months post partum was 15.4 feeds/24 h. 3. The milk yield of one mother fully breast-feeding 2.5-month-old triplets was 3.08 $\mathrm{kg} / 24 \mathrm{~h}$ and the infants were fed twenty-seven times in $24 \mathrm{~h}$. 4. The concentration of lactose, protein and mixed fat in the milk from individual breasts of mothers fuily breast-feeding their infants ranged from 65.6 to $82.2,7.8$ to 15.7 and 16.7 to $46.2 \mathrm{~g} / 1$ respectively. For the three mothers partially breast-feeding 12-month-old infants the values ranged from 54.8 to $71.8,14.2$ to 19.9 and 4.7 to $40.5 \mathrm{~g} / 1$ respectively. 5. At 6 and 12 months of age, the proportion of the total energy intake of the infants which was derived from breast milk ranged from 64 to $100 \%$ and 6 to $13 \%$ respectively. 6 . It is concluded that the maximum potential milk yield for women may be higher than the often quoted value of $700-800 \mathrm{ml} / 24 \mathrm{~h}$.

Salle $B$ see Delorme C

Santog-Ramos R see Brown CE

Sarna $\mathbf{S}$ see Kaprio $J$

Sarna $S$ see Rose RJ

Sasazuki T, Harada F, Kawasali T: Genetic analysis of Kawasaki disease. Prog Clin Biol Res 1987; 250:251-5

Schelley S see Holbrook RH JR

Schoen $M$ see Landy $H J$

Schovenborg $L$ see Lyndrup $J$

Schultz Larsen F see Husby S

Sears RT see Hitchcock A

Seeds JW, Herbert WN, Richards DS: Prenatal 


\section{AUTHOR SECTION}

sonographic diagnosis and management of a twin pregnancy with placenta previa and hemicardia. Am J Perinatol 1987 Oct;4(4):313-6

The sonographic diagnosis of a twin pregnancy complicated by acardius anceps of one fetus, total placenta previa, uterine overdistension, and preterm labor is presented and management is discussed. Attempted selective fetocide is described, but was not successful. Clinical management of severe discordant sonographic dysmorphology is discussed, and diagnostic criteria for sonographic diagnosis of acardia are presented.

Selby JV see Newman B

Senterre J see Verloes A

Serr DM see Rabinovici $J$

Shalev E, Zuckerman H: Conjoined twins in triplet pregnancy [letter] Am J Obstet Gynecol 1987 Nov; 157(5):1323

Shelef $M$ see Goldman JA

Shermeta DW see Olson LM

Short TG, Forrest P, Galletly DC: Paradoxical reactions to benzodiazepines--a genetically determined phenomenon? Anaesth Intensive Care 1987 Aug: 15(3):330-1

Silberg JL, Martin NG, Heath AC: Genetic and environmental factors in primary dysmenorrhea and its relationship to anxiety, depression, and neuroticism. Behav Genet 1987 Jul;17(4):363-83

Slemenda C see Newman $B$

Sletten $\mathbf{K}$ see Husby $G$

Smith CK see Friedrich WN

Smith FE see Husby $G$

Soares I see Delorme $C$

Soernes T, Bakke T: The length of the human umbilical cord in twin pregnancies. Am J Obstet Gynecol 1987 Nov; $157(5): 1229-30$

A current hypothesis on the linear growth of the umbilical cord states that cord length is a function of fetal intrauterine motor activity. If there is some type of intrauterine constraint, the tensile forces on the cord will be diminished, and cord length at term will be shorter than if no such constraint is present. One would expect that the voluntary movements of twins would develop under a constraint and that they would have less free space to move compared with single fetuses. If this hypothesis is valid, cord lengths of twins at term would be shorter than those of single pregnancy infants. We measured the cord lengths of 118 infants in 59 twin births and compared them with cord lengths in 9601 single pregnancies. We found that on the average, the umbilical cord length of the twins was $7.90 \mathrm{~cm}$ shorter than that of single pregnancy infants.

Sperber GH see Machin GA

Strand RD see Winston KR

Sundström C see Jakobson AM

Surtees RA, Price DA: Growth hormone deficiency in one of identical twins. Acta Paediatr Scand 1987 Sep; 76(5):837-8

Suslak L, Mimms GM, Desposito F: Monozygosity and holoprosencephaly: cleavage disorders of the 'midline field'. Am J Med Genet 1987 Sep; 28(1):99-102

\section{$\mathbf{T}$}

Tambs K: No genetic effect on variation in field dependence: a study of rod-and-frame scores in families of monozygotic twins. Behav Genet 1987 Sep;17(5):493-502

Tedesco TA see Hager JM

Telkari JM: Myopia and stature.
Acta Ophthalmol (Copenh) 1987 Dec;65(6):673-6 The association of myopia and height, weight and body-mass index was examined by two methods: a case control method and a co-twin control method. One hundred eightyseven myopic ( 57 males and 130 females) and 603 non-myopic (335 males and 268 females) subjects were studied in the first study. Among males the myopic subjects were taller compared to the non-myopic subjects ( $P$ less than 0.05 ). Among females such difference could not be found. Weight was not statistically significantly different in these two groups in either sex. When the myopic twin partners were compared to the non-myopic co-twins, a statistically significant difference in body mass index could again be noticed among males ( $P$ less than 0.01 ) but not among females. The difference in social class did not explain the previous associations.

Teikari JM: Genetic factors in open-angle (simple and capsular) glaucoma. A population-based twin study. Acta Ophthalmol (Copenh) 1987 Dec;65(6):715-20 A nationwide record linkage of the Finnish Twin Cohort Study (FTCS) with the Hospital Discharge Registry and the Registry of Rights for Free medication is presented. This study consists of 108 pairs (114 individuals) of twins with chronic open-angle glaucoma. Of the twin pairs 29 were monozygotic (MZ), while 79 pairs were dizygotic (DZ). Three monozygotic and 3 dizygotic pairs were concordant for chronic open-angle glaucoma

(OAG), while 26 monozygotic and 76 dizygotic pairs were discordant. Seventy-three twins had chronic simple glaucoma, while 34 twins had capsular glaucoma, and in 7 patients chronic simple glaucoma was noted in one eye and capsular glaucoma in the second eye. The heritability of chronic open angle glaucoma was $13 \%$. The higher $\mathrm{O} / \mathrm{E}$-ratio of concordant twin pairs among $M Z$ twins indicates that genetic factors play a role in this disease. The difference is anyhow surprisingly low compared to former estimates of heritability of open angle glaucoma. The steep rise in prevalence in older age groups was confirmed. The age-adjusted prevalence of chronic open-angle glaucoma in this study was $0.63 \%$.

Teikari JM, Airaksinen PJ, Kaprio J, Koskenvuo M: Primary open-angle glaucoma in 2 monozygotic twin pairs. Acta Ophthalmol (Copenh) 1987 Oct; 65(5):607-11

Two monozygotic twin pairs with primary open-angle glaucoma (POAG) derived from the Finnish Twin Cohort Study were studied. The first female twin pair was concordant and the second female pair was discordant for primary open-angle glaucoma. The nondiseased member of this second pair showed preglaucomatous signs in the form of ocular hypertension. The clinical study of the patients included a careful ophthalmologic examination, retinal nerve fiber layer (RNFL) photography and optic disc stereophotography. Visual fields were tested with an automated perimeter (Octopus 2000). The small number of twin pairs in the present study does not permit quantitative analysis of heritability, but it is obvious that whenever a clinical diagnosis of primary open-angie glaucoma in a monozygotic twin is made, the co-twin should be carefully examined. Tellegen A see Lykken DT

Terrenato L, Novelletto A: Secular trend of twin concordance in late fetal death. Ann Hum Genet 1986 Jan;50 ( Pt 1):63-8

In the present paper the secular trend of twin concordance for late fetal death rate has been 


\section{AUTHOR SECTION}

analysed. The results show that, while the correlation remains unchanged in $\mathrm{MZ}$ twins, it is greatly reduced in $D Z$ twins. This renders untenable the assumption of comparable secular trends in the intrauterine environment of the two types of twins. An appropriate model is given for the estimation of the environmental (intrauterine) factors in late fetal concordance, under the assumption of a wide range of frequencies for unconditional lethals.

Thiene G see Rossi MB

Thomas A Jr see Ziegelbaum M

Tooley WH see Davis SL

Torgersen AM: Longitudinal research on temperament in twins. Acta Genet Med Gemellol (Roma) 1987; $36(2): 145-54$

The changing influence of genetic factors of temperamental individuality has been studied longitudinally in a group of $\mathbf{4 4}$ same-sexed twin pairs at four different ages from infancy to puberty. Previous results showed that genetic factors seemed to play an important role in the development of temperamental characteristics when the twins were in infancy and at six years of age. The present report shows that when the within-pair differences in temperament are studied again at age 15 years, the similarity of identical pairs is even higher than at earlier ages. When shared and nonshared stress in the twin pairs was assessed at this age, some interactions were found between within-pair differences in temperament, stress and zygosity.

Torgersen S: Sampling problems in twin research. J Psychiatr Res 1987;21(4):385-90

Sampling problems related to twin problems may be of at least three kinds: small samples, self-selection and unrepresentative ascertainment. The article mostly discusses the third type of sample problem. Data from a nationwide Norwegian twin study show that the results of twin studies will be quite different depending upon the ascertainment procedure. According to both the ICD-9 as well as the DSM-III classification system, only samples ascertained from mental hospitals treating severe cases are able to demonstrate hereditary factors of any strength.

Torpier $\mathbf{G}$ see Lepelley $\mathbf{P}$

Tosti A, Melino M, Veronesi S: Hand dermatitis and contact sensitivity in twins. Contact Dermatitis 1987 Aug;17(2):113-4

Tosti A, Guerra L, Bettoli V, Bonelli U: Solid facial edema as a complication of acne vulgaris in twins [letter] J Am Acad Dermatol 1987 Nov; $17(5 \mathrm{Pt}$ 1):843-4

True $W$ see Eisen $S$

True $\mathbf{W}$ see Goldberg J

Tung KS see Husby G

Usher RH see Arnold C

\section{V}

Van Den Broeke $\mathbf{C}$ see Fagard $\mathbf{R}$

Verloes A, Lambrechts L, Senterre J, Lambotte C: Microcephalic osteodysplastic dwarfism (type II-like) in siblings. Clin Genet 1987 Aug;32(2):88-94 We report about two sibs showing a common pattern of birth defects, with a pedigree suggestive of autosomal recessive heredity. The main features are intrauterine growth failure with very low birthweight; disproportionate dwarfism with predominantly distal shortening of limbs; small cubitally inclined clenched hands; microcephaly with Seckel-like facies and delayed psychomotor development. $X$-ray findings include metaphyseal flare, $V$-shaped femoral metaphyses and bowing of forearms. Primordial microcephalic osteodysplastic dwarfism Type II is discussed. Metabolic and nutritional data are presented and discussed.

Veronesi $\mathbf{S}$ see Tosti A

Vieregge P: Gilles de la Tourette's syndrome in monozygotic twins [letter] J Neurol Neurosurg Psychiatry 1987 Nov; $50(11): 1554-6$

Vinall PS see Karamatsu JT

Vintzileos AM see Rodis JF

\section{$\mathbf{W}$}

Ware R, Kurtzberg J, Brazy J, Falletta JM: Congenital Pelger-Huet anomaly in triplets. Am J Hematol 1988 Mar;27(3):226-7

Congenital Pelger-Huet anomaly is an autosomal dominant disorder characterized by incomplete nuclear segmentation of granulocytes. The morphology of these mature but hyposegmented granulocytes may be confused with that of immature granulocytes (bands), thereby suggesting bacterial infection. We report the first known case of triplets with this condition, and emphasize the need to identify accurately this normal variant.

Warren $\mathbf{P}$ see Wass $\mathbf{D}$

Wass D, Bennett M, Garrett W, Warren P: Selective termination in the first trimester [letter]

Aust N Z J Obstet Gynaecol 1987 May;27(2):171-2

Weingold AB see Landy $\mathrm{HJ}$

Welch JP see Winsor EJ

Westermark $P$ see Husby $G$

Whaley $K$ see Fyfe $A$

Whalley PJ see Brown CE

Wiggins AD see Franti CE

Williams $M$ see Hay DA

Williams RC Jr see Husby G

Wilson RS: A new method for representing mental growth. Acta Genet Med Gemellol (Roma) 1987; $36(2): 121-34$

A new method is described for plotting the growth in mental development from birth to adolescence. Using data from a large sample of twins followed since birth, a dimension of mental growth was constructed by arraying all tests in order of difficulty, then computing the average gain from age to age. The gain was expressed in standard-deviation units, which reflected the upward shift in the score distribution from time $X$ to time $X+1$. When cumulated over ages, the scores generated a mental growth curve for the sample as a whole, as well as for each case individually. The curves displayed a very rapid gain in mental growth over the first 24 months of life, with the complexity of mental functions advancing by nearly 20 standard deviations from birth to two years. Thereafter the gain progressively tapered off until reaching a final increment of $0.5 \mathrm{SD}$ gain between 15 years and adulthood. At this point, the terminal level of mental growth reached an average value of 31 SD units, with a spread of individual differences equal to $+/-$ 3 SD units. The scores at each age represented a combination of base level plus gain from the preceding age, and during infancy the gain scores were large in relation to base. At later ages, however, the gain scores were comparatively small, both in absolute terms and in relation to base. These characteristics help explain the typical low-order 


\section{AUTHOR SECTION}

correlations obtained among mental test scores during infancy, vs the progressively larger correlations obtained at later ages.

Winsor EJ, Brown BS, Lather ER, Heifeta SA, Welch JP: Deceased co-twin as a cause of false positive amniotic fluid AFP and AChE. Prenat Diagn 1987 Sep; 7(7):485-9

A pregnancy was terminated because of persistently elevated amniotic fluid AFP (+10 S.D.) and an AChE band of low intensity on gel electrophoresis. No fetal anomalies were detected by

ultrasonographic examination. Autopsy revealed an apparently normal fetus of about 20 weeks gestation. Attached to the placenta was a small sac containing a fetus papyraceus co-twin of about 8-9 weeks gestation. The small deceased co-twin and its gestational sac were not detected prenatally despite multiple ultrasonographic examinations. The difficulty in the interpretation of apparently conflicting results is emphasized.

Winston KR, Rockoff MA, Mulliken JB, Strand RD, Murray JE: Surgical division of craniopagi. Neurosurgery 1987 Dec;21(6):782-91 (57 ref.)

The worid's surgical experience on the division of craniopagi is reviewed, and a new case is reported. The problems, including ethical considerations, that must be addressed in selecting patients for operation and in preparing for the procedure are discussed in detail. Hemodynamic stability and the problem of intraoperative gravitational distortion of the brain are addressed. The importance of careful planning is stressed. Survival of the 31 craniopagi after operation is discussed in relation to types of junction.

Winston KR: Craniopagi: anatomical characteristics and classification. Neurosurgery 1987 Dec; 21(6):769-81 (122 ref.)

The incidence, embryology, anatomical features of the site of junction, associated abnormalities, and survival of the 79 craniopagi reported from 1496 to 1987 have been reviewed. All craniopagi upon whom sufficient information is available have been classified on the basis of the deepest shared anatomical structure.

Wittmann BK see Farquharson DF

Wittmann BK see O'Keane JA

Wood PD see Christian JC

\section{$\mathbf{Y}$}

Yovich J, Mulcahy M, Matson P: IVF and Goldenhar syndrome [letter] J Med Genet 1987 Oct:24(10):644

Yu PL see Christian JC

Yuen BH see Farquharson DF

Yuen BH see O'Keane JA

\section{$\mathbf{Z}$}

\section{Zachary AA see Zlegelbaum $M$}

Zandecki $M$ see Lepelley $\mathbf{P}$

Zerbin-Rïdin E: Psychiatric genetics and psychiatric nosology. J Psychiatr Res 1987;21(4):377-83 (49 ref.) At the present time, family and twin data are used in psychiatry to test clinical concepts at issue, and, in particular, to validate or reject diagnostic classifications. The dichotomy between the schizophrenias and the effective disorders, as suggested by Kraepelin, has been supported by contemporary family and twin studies and also is corroborated by modern family and adoption studies. In the atypical psychoses it is demonstrated impressively how family data vary with different sampling procedures and diagnostic practices. In the affective disorders, the family findings at first favored the separation of unipolar and bipolar disorders but, subsequently, this concept was questioned and revised. Currently, psychiatric genetics attempts to contribute to the understanding of the affective disorders, in particular the depressions, by delineating subgroups and by looking for possible genetic relations between depression and frequently associated disorders, such as anxiety or anorexia.

Ziegelbaum M, Thomas A Jr, Zachary AA: The association of Peyronie's disease with HLA B7 cross-reactive antigens. A case report of identical twins. Cleve Clin J Med 1987 Sep-Oct;54(5):427-30 Zoma A see Fyfe A

Zuckerman H see Shalev E 